\title{
Maintaining a Technology- Neutral Approach to Hydrogen Production Process Development Through Conceptual Design of the Next Generation Nuclear Plant
}

Michael W. Patterson

Charles V. Park

May 2008

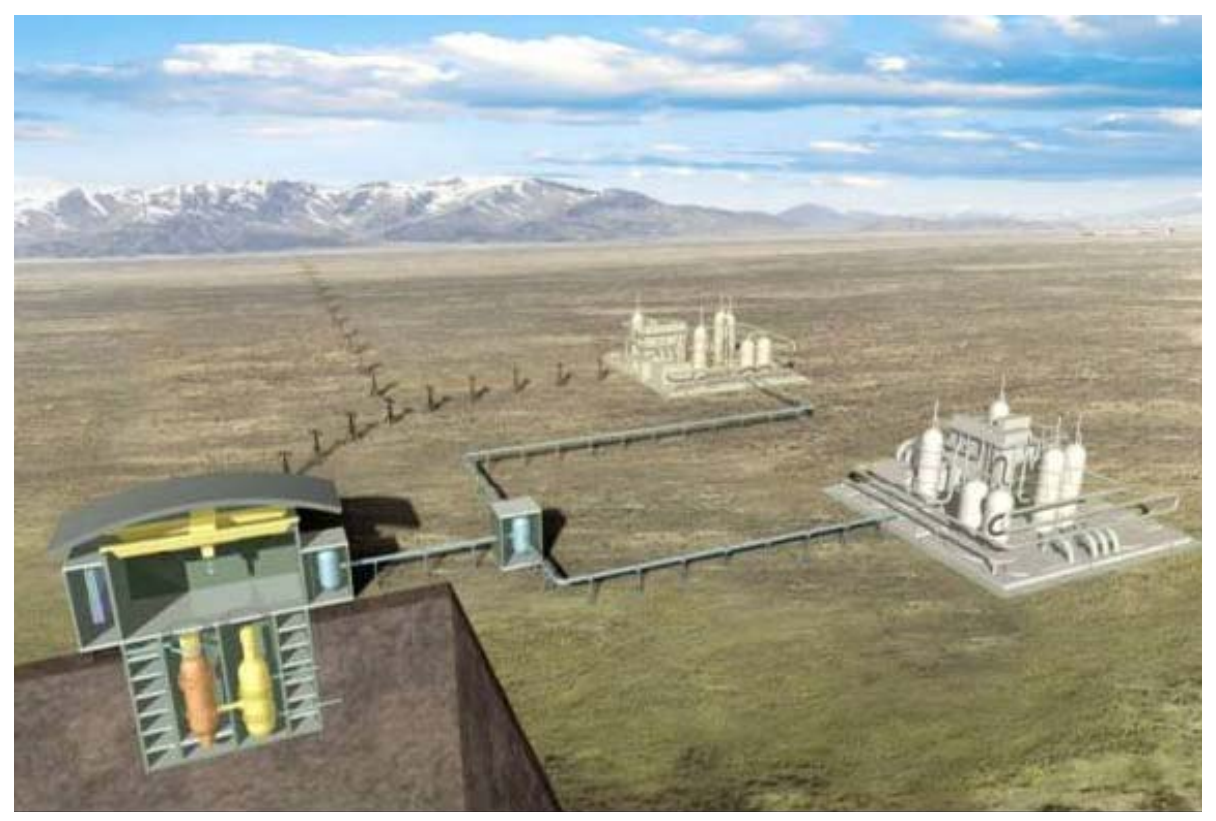

The INL is a U.S. Department of Energy National Laboratory operated by Battelle Energy Alliance 
INL/EXT-08-14193

\title{
Maintaining a Technology-Neutral Approach to Hydrogen Production Process Development Through Conceptual Design of the Next Generation Nuclear Plant
}

Michael W. Patterson

Charles V. Park

May 2008

\author{
Idaho National Laboratory \\ Next Generation Nuclear Plant Project \\ Idaho Falls, Idaho 83415
}

Prepared for the

U.S. Department of Energy

Office of Nuclear Energy

Under DOE Idaho Operations Office

Contract DE-AC07-05ID14517 


\section{DISCLAIMER}

This information was prepared as an account of work sponsored by an agency of the U.S. Government. Neither the U.S. Government nor any agency thereof, nor any of their employees, makes any warranty, expressed or implied, or assumes any legal liability or responsibility for the accuracy, completeness, or usefulness, of any information, apparatus, product, or process disclosed, or represents that its use would not infringe privately owned rights. References herein to any specific commercial product, process, or service by trade name, trade mark, manufacturer, or otherwise, does not necessarily constitute or imply its endorsement, recommendation, or favoring by the U.S. Government or any agency thereof. The views and opinions of authors expressed herein do not necessarily state or reflect those of the U.S. Government or any agency thereof. 
Maintaining a Technology-Neutral Approach to Hydrogen Production Process Development

Revision 0

INL/EXT-08-14193

May 2008

Next Generation Nuclear Plant Project

Maintaining a Technology-Neutral Approach to Hydrogen Production Process Development through Conceptual Design of the Next Generation Nuclear Plant

INL/EXT-08-14193

Revision 0

May 2008

Approved by:
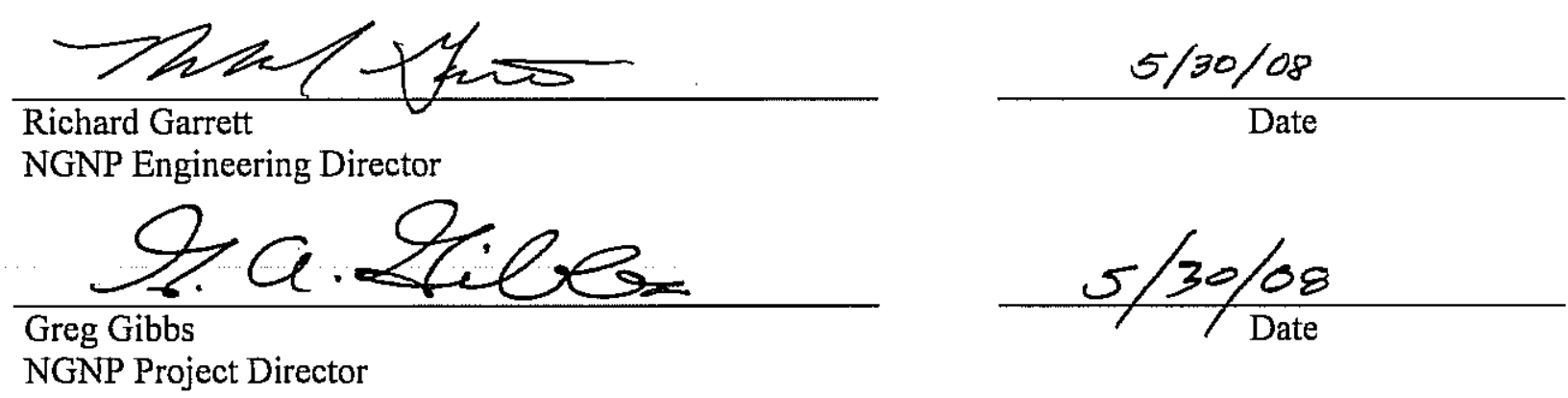

iv 


\section{EXECUTIVE SUMMARY}

The Energy Policy Act of 2005 (EPAct) charges the Department of Energy (DOE) with developing and demonstrating the technical and economic feasibility of using high temperature gas reactor (HTGR) technology for the production of electricity and/or hydrogen. The hydrogen processes that will be demonstrated in the Next Generation Nuclear Plant (NGNP) Project are being developed in a parallel DOE project under the Nuclear Hydrogen Initiative (NHI). The NGNP Project team analyzed the design, cost, and schedule impact of maintaining a technology-neutral approach for hydrogen process development through conceptual design of the NGNP. Currently, the NHI is performing parallel research and development (R\&D) on three hydrogen production processes - a technology neutral approach. While the objectives of the NGNP Project and NHI are consistent, comparisons of the individual schedules show that the NHI schedule does not meet the needs of the NGNP Project. Specifically, NHI plans to select two hydrogen processes for further development in 2011 and recommend a final process for demonstration in 2015. The NGNP Project expects to complete conceptual design at the end of FY 2010, at which time (or before) the hydrogen process to be demonstrated should be selected. This analysis compares acceleration of the hydrogen process down-selection at the completion of the NGNP Project conceptual design to the current NHI plan. It was performed to improve integration of the hydrogen process development and NGNP Project schedules, and fulfills milestone G-IN07NG07-90 Complete an analysis of the design, cost and schedule ramifications for maintaining a technology neutral hydrogen production process for NGNP through the conceptual design phase.

The NGNP Project intends to design and construct a prototype high temperature gas-cooled reactor HTGR. A component test facility (CTF) is planned to support testing and demonstration of HTGR technologies, including those for hydrogen production. The demonstrations will support scheduled design and licensing activities, leading to subsequent construction and operation of the HTGR. Demonstrations in the CTF are expected to start about two years earlier than similar scale hydrogen process demonstrations planned by NHI. Selection of the hydrogen process to coincide with the end of NGNP conceptual design will reconcile many of the schedule conflicts and hence, was chosen as basis for schedule acceleration. The principal results, conclusions and recommendations of the analysis are as follow:

- Accelerating the schedule to maintain a technology neutral approach only until the completion of conceptual design and then making an early selection of the hydrogen process for NGNP is feasible and recommended. In part, as a result of reduction in the current funding for the NHI program, this early selection in FY 2010, however, may occur before the development of the candidate hydrogen process technologies have progressed to the point that predicts success at a commercial scale. It is recommended therefore, that the hydrogen production process down-selection should identify the primary hydrogen process for demonstration and also a back-up process if the primary process development is not successful. Development of the back-up process should continue at a slower pace until the primary process reaches technical readiness level (TRL) 5 on the NGNP technical readiness scale, which indicates the technology is likely to successfully scale up to commercial application. Maintaining development of the back-up process for a short period of time is an affordable and reasonable risk management strategy.

- Cost avoidance from early selection may be as high as $\$ 160$ million. This maximum cost avoidance results from eliminating work on all unselected processes and depends on which process is selected for demonstration. Developing a back-up process reduces the cost avoidance by $\$ 9$ million to $\$ 24$ million, depending on which process is chosen as the back-up. Current cost estimates are very immature and only a rough order of magnitude, but sufficient to identify that significant savings can be realized. Development of a rigorous life cycle cost estimate and schedule for each hydrogen 
production process is recommended. This information should be used in establishing a long-term plan that is consistent between the NGNP Project and NHI, and should also inform future decisions.

- As part of the analysis of design ramifications, a systems-engineering approach was used to define the decision-making process and criteria for selecting the primary and back-up hydrogen processes. These are summarized in Figure 8, Decision tree for hydrogen production process down-selection. Performance of these activities during conceptual design is recommended to discriminate between hydrogen technologies and inform the process selection.

- The NGNP Project will rely heavily on engineering scale testing of the hydrogen process in the CTF to prove the technical capabilities and reliability of the process before installation in the HTGR. CTF is currently expected to be available for testing in FY 2014 and it is important that the design of the $\mathrm{CTF}$ and the schedule for testing in this facility support the timely development of the selected process. It is recommended that the development of the functional and operating requirements and configuration of the $\mathrm{CTF}$ accommodate testing any of the hydrogen processes under consideration at a commercial scale.

- An early selection will accelerate hydrogen process testing in the CTF and provide more timely and necessary data required for support of NGNP licensing by the Nuclear Regulatory Commission (NRC). For example, establishing hazards and transient operating conditions will support development of bounding interface conditions to be used in design and licensing of the nuclear heat supply system.

- Additional evaluations of the feasibility and advantages of use of the CTF rather than NGNP to perform the commercial-scale demonstration required by the EPAct are recommended. The evaluation should include analysis of the need to revise the EPAct.

Finally, this effort has demonstrated the need to have better coordination of the NGNP and NHI program objectives and schedules. The NHI's programmatic purpose to develop hydrogen production technologies that can be coupled to nuclear reactors is broader than the NGNP Project's objective regarding hydrogen production. The NGNP Project's specific design, licensing, development and commercialization-support objectives are directed toward establishing the technical and licensing basis for the HTGR technology to provide process heat to a broad range of potential end-user applications including the production of hydrogen as an energy carrier. The Project needs to choose the best available hydrogen production technology that is technically and economically viable, and supports the project schedule.

NHI could be expected to continue pursuing alternative technologies that improve the economics, and technical and environmental viability with a development schedule that may extend beyond the NGNP Project. Accordingly, the schedule and objectives for NHI process development activities that affect the NGNP heat transfer and transport systems and the development of interface requirements for the hydrogen process and other factors affecting the design and licensing of NGNP, (e.g., establishing external hazards, transient responses to upset in the hydrogen production facility) must be set by the NGNP Project. Funding for these activities by NHI should be included in the budget of and be controlled by the NGNP Project. The requirements and funding for completion of NHI commitments to the NGNP Project shall be established and controlled through close collaboration and formal agreements, (e.g., future contracts) between the NHI and the NGNP Project that support the design, licensing and schedule for NGNP. Section 4.2 of the report summarizes responsibilities of NHI and NGNP in this regard. 


\section{CONTENTS}

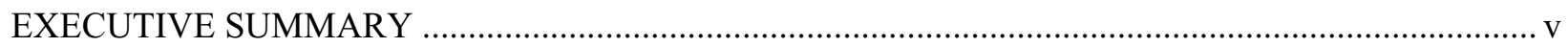

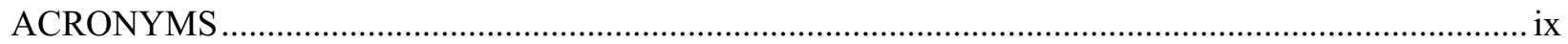

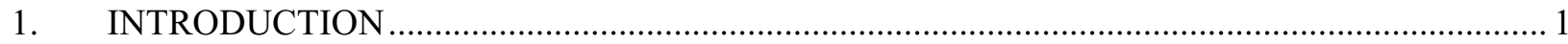

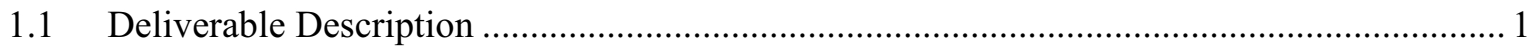

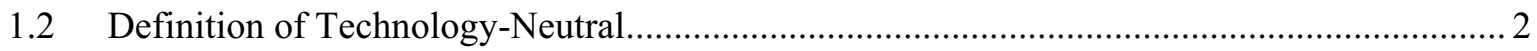

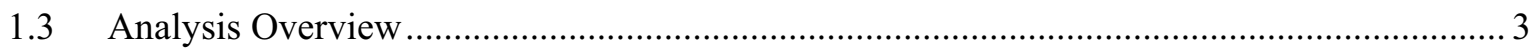

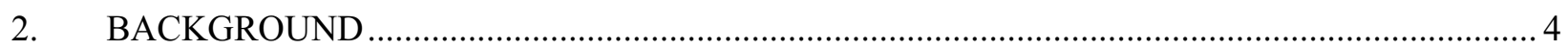

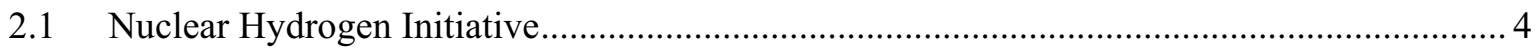

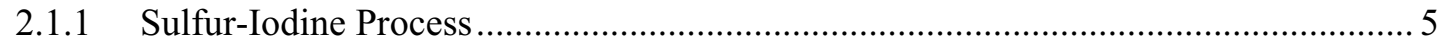

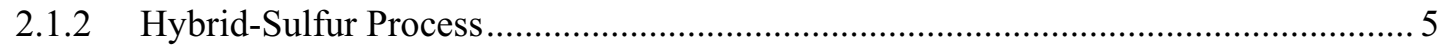

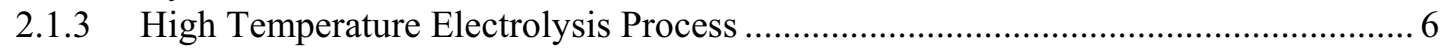

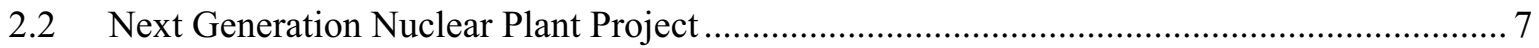

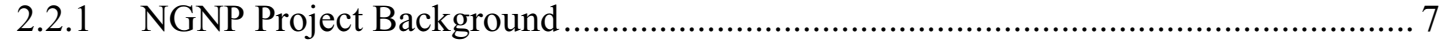

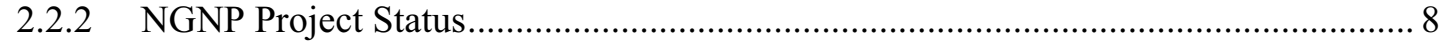

3. ANALYSIS OF MAINTAINING A TECHNOLOGY-NEUTRAL APPROACH........................9

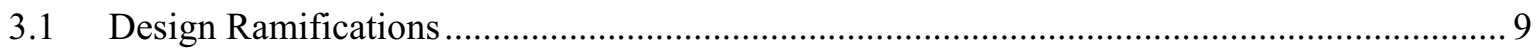

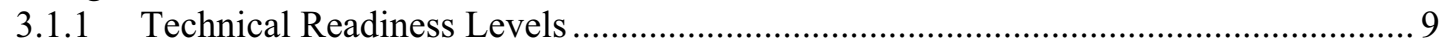

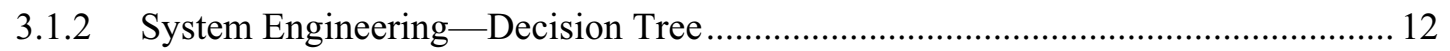

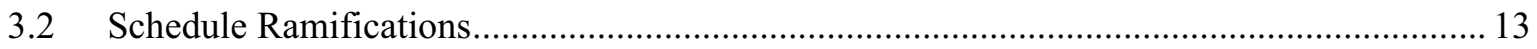

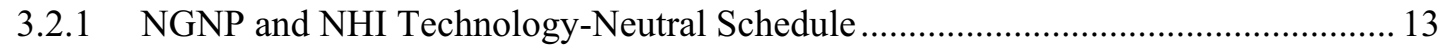

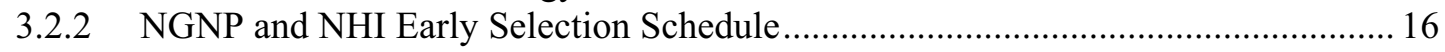

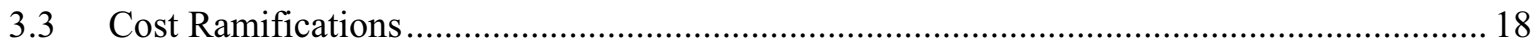

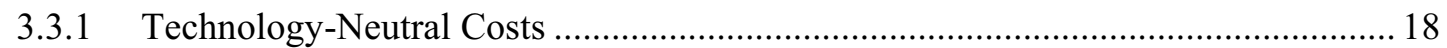

3.3.2 Early Selection Costs ............................................................................................. 19

3.3.3 Risk Reduction versus Cost Avoidance from Early Technology Selection ............... 19

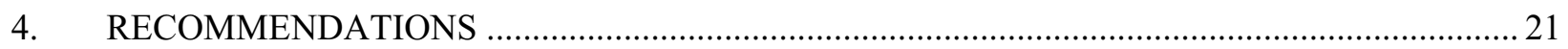

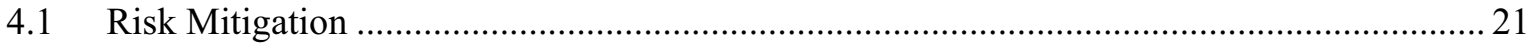

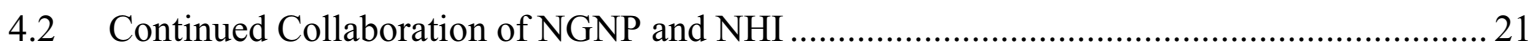

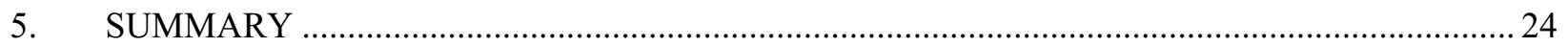

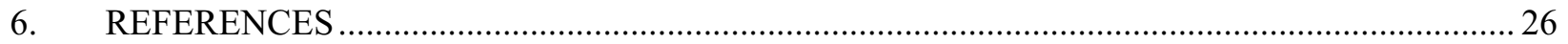




\section{FIGURES}

Figure 1. NHI plan for technology-neutral development.................................................................. 2

Figure 2. Major reactor-hydrogen interface and balance of plant systems. ........................................... 4

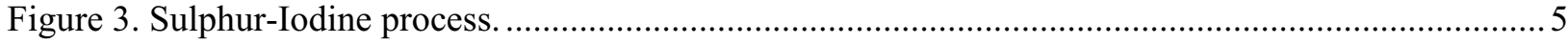

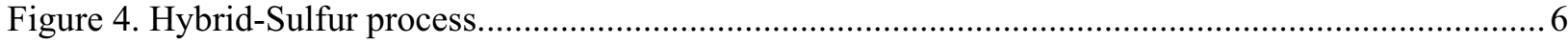

Figure 5. HTE processes in a high temperature solid oxide electrolysis cell.......................................... 7

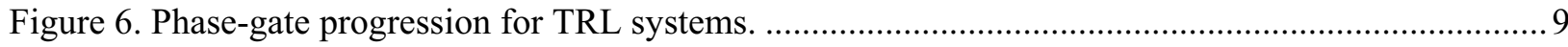

Figure 7. TRL equivalencies for NHI, EERE, DoD/NASA, and NGNP Project................................... 10

Figure 8. Decision tree for hydrogen production process down-selection............................................... 12

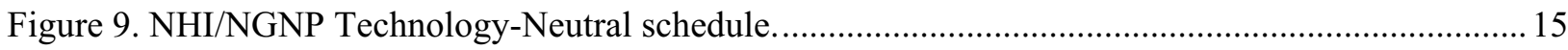

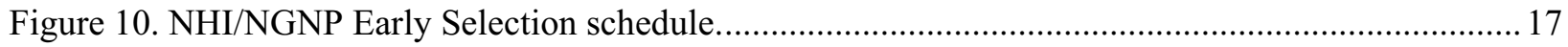

\section{TABLES}

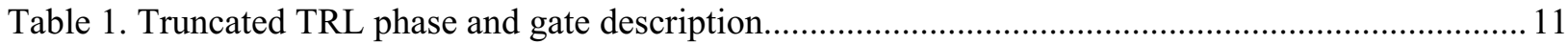

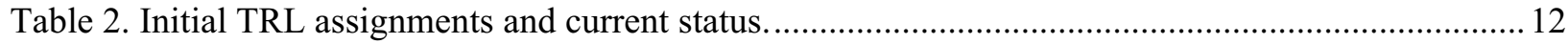

Table 3. Research and development cost $(\$ \mathrm{~K})$ for technology-neutral................................................... 18

Table 4. Research and development cost (\$K) for early selection......................................................... 19 


\section{ACRONYMS}

ASME American Society of Mechanical Engineers

ASTM American Society for Testing and Materials

CD Critical Decision

$\mathrm{COL} \quad$ Combined Construction and Operating License

CTF component test facility

DOE U.S. Department of Energy

EERE Office of Energy Efficiency and Renewable Energy

EM Office of Environmental Management

EPAct Energy Policy Act of 2005

FWP Field Work Proposals

GAO Government Accountability Office

GEN-IV fourth generation

HI hydrogen iodide

HTE High Temperature Electrolysis

HTGR high temperature gas-cooled reactor

HTS heat transfer system

HyS Hybrid-Sulfur

INL Idaho National Laboratory

NASA/DoD National Aeronautics and Space Administration/Department of Defense

NE Office of Nuclear Energy

NEPA National Environmental Policy Act

NGNP Next Generation Nuclear Plant

NHI Nuclear Hydrogen Initiative

NRC Nuclear Regulatory Commission

PCS power conversion system

PICS Project Information and Control System

PIRT Phenomena Identification and Ranking Tables

R\&D research and development

SI Sulphur-Iodine

TC thermochemical

TRL technology readiness level

VHTR very-high temperature reactor 


\section{INTRODUCTION}

The Next Generation Nuclear Plant (NGNP) Project team analyzed the design, cost, and schedule impact of maintaining a technology-neutral approach for hydrogen process development through conceptual design of the NGNP. Currently, the Nuclear Hydrogen Initiative (NHI) plans to select two hydrogen production processes in 2011 for further development and select a final process for demonstration in 2015. The NGNP Project will be in final design at that time and intends to start site work in preparation for construction by 2015 . This analysis compares acceleration of the hydrogen process down-selection at completion of the NGNP Project conceptual design to the current NHI plan. It was performed to improve integration of the hydrogen process development and NGNP Project schedules. This report fulfills milestone G-IN07NG07-90 Complete an analysis of the design, cost and schedule ramifications for maintaining a technology neutral hydrogen production process for NGNP through the conceptual design phase.

The DOE Office of Nuclear Energy (NE) manages the NGNP and NHI as two separate, but related projects. While the objectives of the NGNP Project and NHI are consistent, the NGNP Project has progressed to the definition phase and the project plan has matured. NHI performs research and development $(\mathrm{R} \& \mathrm{D})$ for multiple nuclear-assisted hydrogen production processes and associated technologies. $\mathrm{R} \& \mathrm{D}$ on three processes is proceeding in parallel - a technology neutral approach. Recommendations to select the process or processes for final demonstration are not planned for several years. Choosing a hydrogen production process for accelerated development, in advance of the recommendations from NHI and as the first hydrogen process for demonstration, is referred to as an early selection in this analysis.

Integrating the NHI and NGNP Project schedules reconciles multiple, complex activities. Multiple potential commercial applications for the NGNP Project require process heat, electricity, steam and hydrogen in varied combinations and sizes. Coupling these processes to the reactor in multiple configurations adds complexity to the design, licensing, and demonstration of both the reactor and the hydrogen production process. Commercial viability of hydrogen production may depend on the specific application and heat transport configuration. A systems-engineering approach was used to define the decision-making criteria for selecting a hydrogen production technology at the end of NGNP conceptual design. Associated design, cost and schedule risks were analyzed and risk mitigation strategies were recommended, including provisions to maintain close collaboration between the NGNP Project and NHI.

\subsection{Deliverable Description}

Section 1.3 of the FY 2008 INL Performance Evaluation Measurement Plan (Contract No. DE-AC0705ID14517) contains the following description of this analysis:

Complete by May 31, 2008, an analysis of the design, cost and schedule ramifications for maintaining a technology neutral hydrogen production process for NGNP through the conceptual design phase. The analysis will include an assessment of maintaining a technology neutral concept versus selecting a hydrogen production process in advance of the recommendations from the Nuclear Hydrogen Initiative. The analysis will also include a recommended course of action, including provisions for close collaboration with the Nuclear Hydrogen Initiative.

Choosing a hydrogen production process for accelerated development at the end of NGNP conceptual design, in advance of the recommendations from NHI and as the first hydrogen process for 
demonstration, is considered an early selection. A technology-neutral approach would be maintained until the selection is made. Early selection is compared to maintaining the technology-neutral schedule (e.g., deferred down-select) for several years as currently planned by NHI.

\subsection{Definition of Technology-Neutral}

NHI plans in 2007 were to develop three processes-Sulfur-Iodine (SI), Hybrid-Sulfur (HyS), and High Temperature Electrolysis (HTE) in parallel - until 2011. A preliminary selection in 2011 would identify the thermochemical (TC) process for scale-up to compare with the HTE process, assuming HTE was judged ready for scale-up also. Two processes were planned for continued development through 2015, at which time one process would be selected for engineering-scale demonstration concluding in 2019. The NHI plan for technology-neutral development is illustrated in Figure 1 and is generally consistent with the schedule for the NGNP Project. NHI experienced funding constraints and the figure has not been adjusted to reflect the resulting changes, although the general philosophy is unchanged. Parallel development of multiple processes to this level of technical maturity is relatively risk-averse and extends the opportunity for one of the several processes to demonstrate exceptional hydrogen production performance.

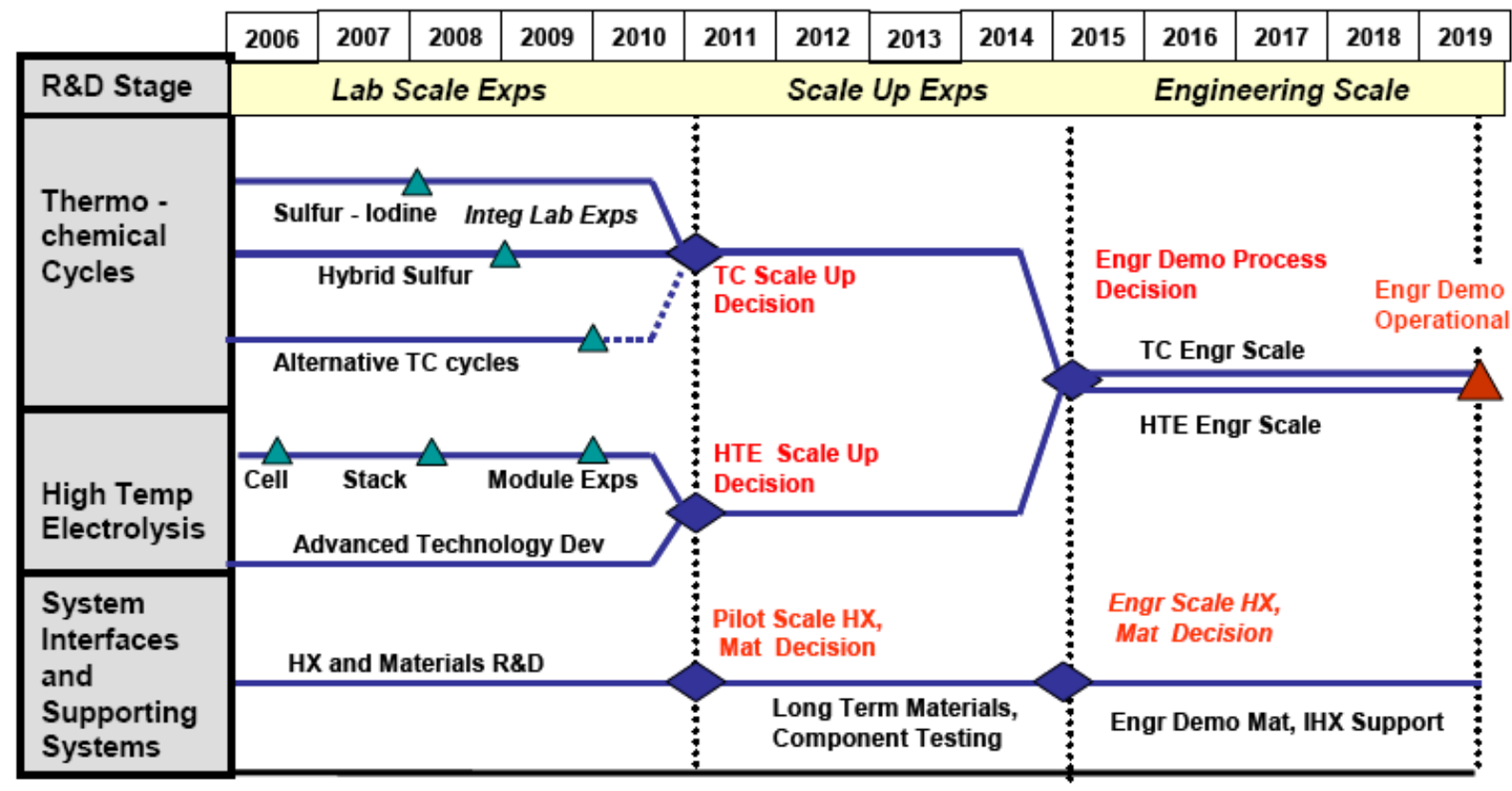

Figure 1. NHI plan for technology-neutral development.

In contrast to the approach shown in Figure 1, making a down-selection when conceptual design is completed would identify one hydrogen production process for first demonstration with the NGNP Project. Scale-up to an engineering demonstration would occur as needed to support design, result in earlier completion, and make data available to inform the NRC licensing process. Information would be available in time to confirm that hazards and transients from the hydrogen production process are bounded by the interface conditions defined for the nuclear heat supply system. 


\subsection{Analysis Overview}

In performing this analysis, the team used a systems-engineering approach to define decision-making criteria to select a hydrogen production technology at the end of conceptual design and to assess current TRLs for the hydrogen process technologies. The relative technical, cost and schedule risks of each approach were analyzed and risk mitigation strategies were recommended, including provisions to maintain close collaboration between the NGNP Project and NHI.

NHI, a component of the DOE Hydrogen Program managed by NE, is investigating multiple approaches to produce cost-effective hydrogen from nuclear energy. Its objective is to develop the technology and information basis for a future decision on commercial viability. The NGNP Project was authorized in the Energy Policy Act of 2005 (EPAct) ${ }^{1}$, which tasks DOE with demonstrating HTGR technology. The demonstration is to include the technical, licensing, operational, and commercial viability of HTGR technology for the production of electricity and hydrogen. These initiatives are clearly interrelated.

While the objectives of the NGNP Project and NHI are generally consistent, the NGNP Project has progressed to the definition phase and the project plan has matured. Multiple potential commercial applications for the NGNP Project require process heat, electricity, steam and hydrogen production in varied combinations and sizes. Coupling these processes to the reactor in multiple configurations complicates the design, licensing, and demonstration of both the reactor and the hydrogen production processes. The commercial viability of hydrogen production may depend on the specific application and heat transport configuration. This analysis helps to further integrate these two ventures. 


\section{BACKGROUND}

The NGNP Project will demonstrate HTGR technology as required by the EPAct and the current target for initial reactor operation is 2021 , followed by a 3-year operating period. The EPAct requires demonstration of hydrogen production from HTGR technology and the NGNP Project is currently in the conceptual design phase ${ }^{2}$. Hydrogen production research is performed by NHI under separate funding and interface with the NHI is provided by the NGNP Project. Previous work related to configurations and component designs of heat transport fluids and systems will also be integrated with the project.

NHI will continue its research of hydrogen production processes, but as the NGNP Project matures, further development of the hydrogen production systems will transition to NGNP to support design and licensing efforts. The configuration in Figure 2 reflects a hydrogen production plant connected to an indirect heat transfer loop; however, multiple configurations with or without process heat application or electrical power production are possible.

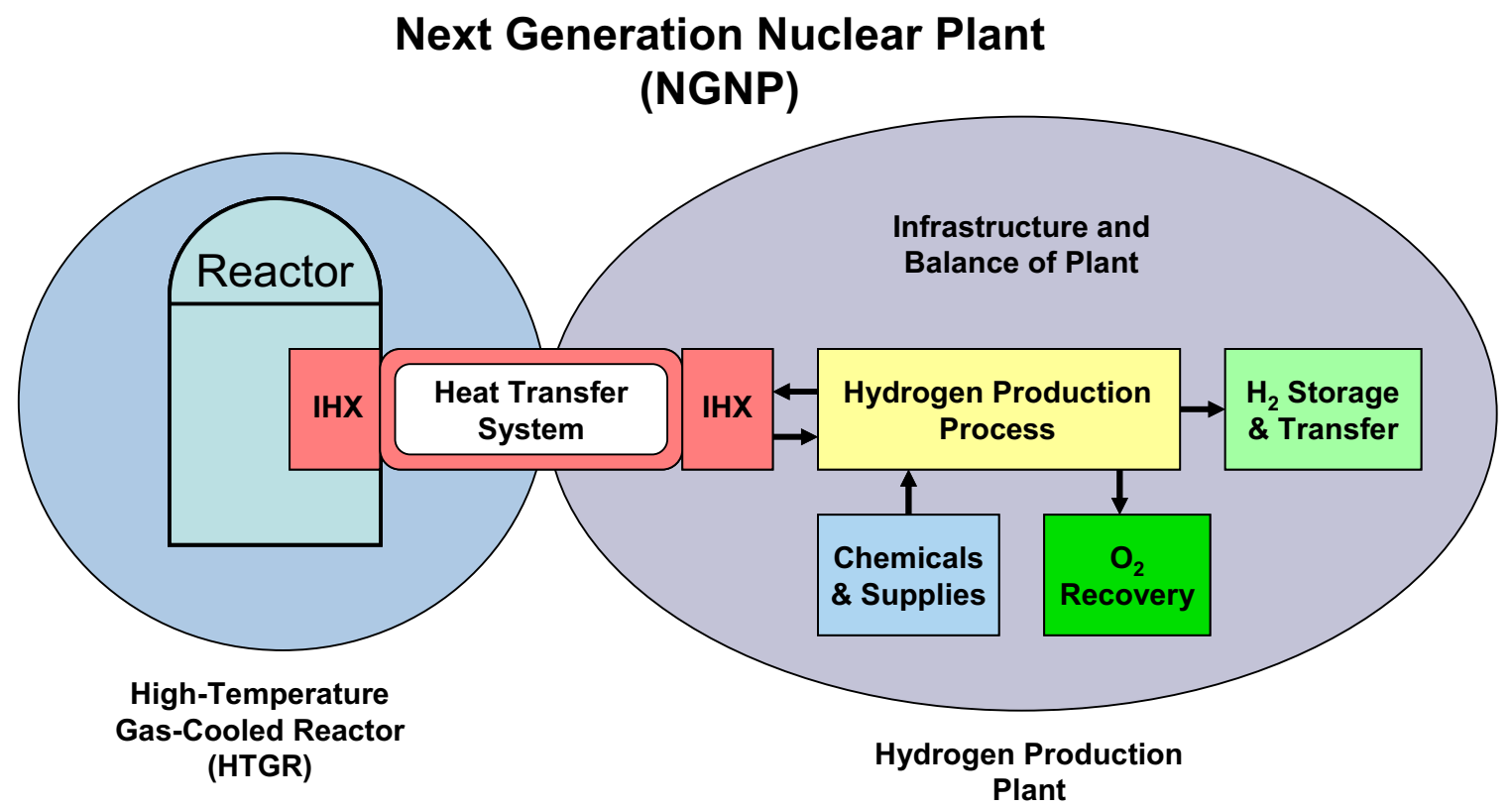

Figure 2. Major reactor-hydrogen interface and balance of plant systems.

\subsection{Nuclear Hydrogen Initiative}

Annual worldwide hydrogen production amounts to 50 million tons ( 555 billion $\mathrm{Nm}^{3}$ ). Hydrogen is mainly used to produce ammonia for fertilizers and in crude oil refining processes. As efficient fuel cells are developed and enter the transportation sector, worldwide demand for hydrogen will increase and may eventually rival the demand for electricity. Highly promising applications are seen in the production of hydrogen as a future energy carrier and as a chemical agent in the refining of crude oil, production of chemicals, and ore reduction. Because of a gradual decline in the average quality of crude oil, increasing amounts of hydrogen will be needed. 
Although hydrogen is the most abundant element in the universe, it does not naturally exist as a free element in large quantities or high concentrations. At a production efficiency of 50\% (chemical energy of hydrogen/reactor thermal energy) and a capacity factor of $90 \%$, the production of 50 million tons of hydrogen would require around $500 \mathrm{GWth}$, which is about half of the world's current nuclear capacity. Given these needs, it is appropriate to develop nuclear energy systems designed for large-scale production of hydrogen.

The very-high temperature reactor (VHTR) hydrogen production program ${ }^{3}$ intends to:

- Develop and optimize the TC water splitting processes of the sulphur family, giving priority to the SI process

- Evaluate alternative TC hydrogen-generation processes

- Advance the HTE process

- Define and validate technologies for coupling reactors to process plants.

The NHI program also assesses and develops other hydrogen producing processes amenable to operation with other fourth generation (GEN-IV) reactor systems.

\subsubsection{Sulfur-lodine Process}

In the SI cycle, iodine and sulphur dioxide are added to water, which causes an exothermic reaction that creates sulphuric acid and hydrogen iodide (HI). The sulphuric acid can be decomposed at about $850^{\circ} \mathrm{C}$, releasing oxygen and recycling sulphur dioxide. The $\mathrm{HI}$ can be decomposed at about $450^{\circ} \mathrm{C}$, releasing hydrogen and recycling iodine. Figure 3 shows the following reactions:

$$
\begin{array}{lll}
2 \mathrm{H}_{2} \mathrm{O}+\mathrm{SO}_{2}+\mathrm{I}_{2} \rightarrow 2 \mathrm{HI}+\mathrm{H}_{2} \mathrm{SO}_{4} & 100^{\circ} \mathrm{C} & \text { (exothermic) } \\
\mathrm{H}_{2} \mathrm{SO}_{4} \rightarrow \mathrm{SO}_{2}+\mathrm{H}_{2} \mathrm{O}+{ }^{1 / 2} \mathrm{O}_{2} & 850^{\circ} \mathrm{C}-900^{\circ} \mathrm{C} & \text { (endothermic) } \\
2 \mathrm{HI} \rightarrow \mathrm{I}_{2}+\mathrm{H}_{2} & 400^{\circ} \mathrm{C}-500^{\circ} \mathrm{C} & \text { (endothermic) } \\
\hline \mathrm{H}_{2} \mathrm{O} \rightarrow \mathrm{H}_{2}+1 / 2 \mathrm{O}_{2} & &
\end{array}
$$

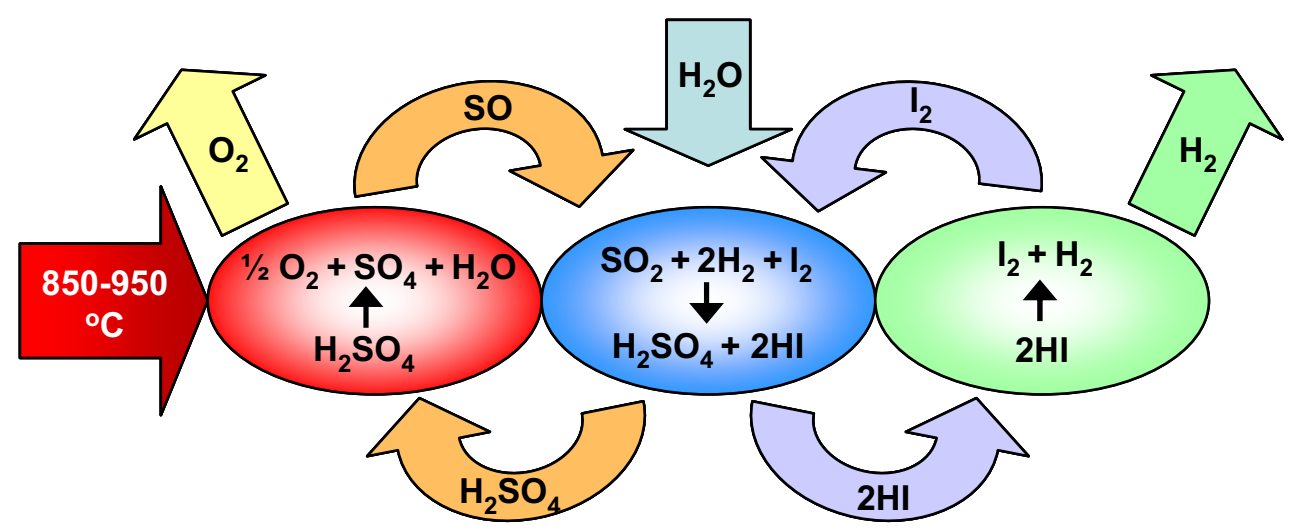

Figure 3. Sulphur-Iodine process.

\subsubsection{Hybrid-Sulfur Process}

The Hybrid-Sulfur (HyS) process is an all-fluids cycle that involves a single electrochemical step and a single TC step. The chemistry involves only sulfur compounds, water, hydrogen, and oxygen. The two process reactions are as follows: 
(1) $\mathrm{SO}_{2}+2 \mathrm{H}_{2} \mathrm{O} \rightarrow \mathrm{H}_{2}+\mathrm{H}_{2} \mathrm{SO} 4$

(2) $\mathrm{H}_{2} \mathrm{SO} 4 \rightarrow \mathrm{H}_{2} \mathrm{O}+\mathrm{SO}_{2}+1 / 2 \mathrm{O}_{2}$ (electrochemical, $80^{\circ} \mathrm{C}-120^{\circ} \mathrm{C}$ )

(thermochemical, $800^{\circ} \mathrm{C}-900^{\circ} \mathrm{C}$ )

The net result of reactions 1 and 2 is the decomposition of water into hydrogen and oxygen. All the sulfur compounds are regenerated and recycled as process intermediates. Reaction 1 is performed in an electrochemical cell, similar to a water electrolyzer. Sulfur dioxide is dissolved in concentrated sulfuric acid (50 wt.\% to $70 \mathrm{wt} . \%$ ) and is used to depolarize the anode of the cell, producing sulfuric acid, rather than oxygen, as the anode product. Figure 4 shows these reactions.

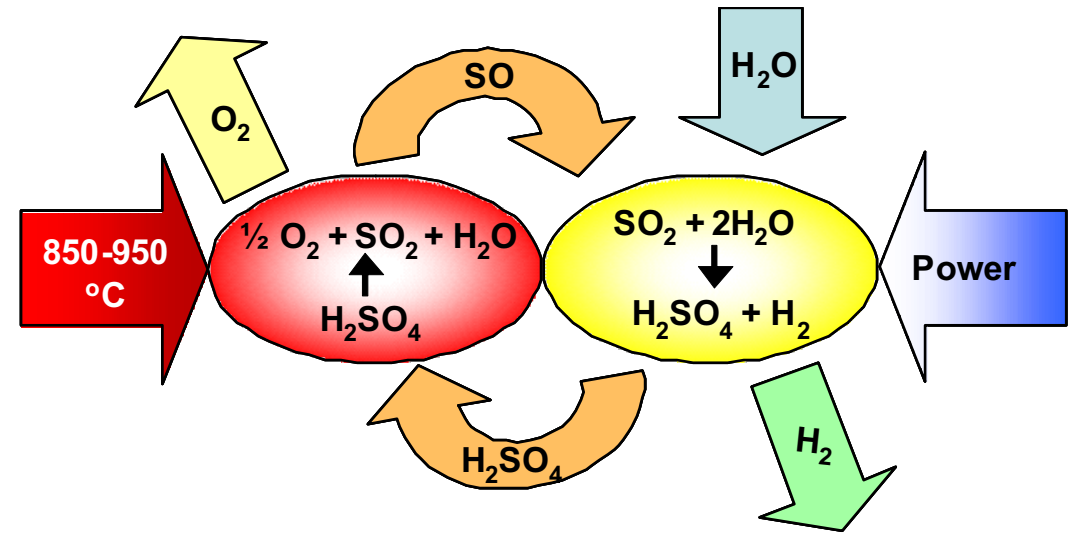

Figure 4. Hybrid-Sulfur process.

\subsubsection{High Temperature Electrolysis Process}

The electrochemical reactions that take place in the HTE solid oxide cell are shown in Figure 5. An inlet stream containing steam at $800^{\circ} \mathrm{C}$ to $830^{\circ} \mathrm{C}$, plus about $10 \%$ hydrogen to maintain reducing conditions, is introduced to one edge of the cell. The water molecules are dissociated at the electrodeelectrolyte interface and the oxygen is transported as $\mathrm{O}^{=}$ions move through the electrolyte. A mixture containing about $90 \%$ hydrogen and the residual steam exits from the opposite edge of the cell. Oxygen molecules are formed at the electrolyte-anode interface and exit from the cell through flow fields adjacent to the anode. In reality, the oxygen flow fields are perpendicular to the plane of the diagram, such that the oxygen and hydrogen are flowing at right angles to one another. 


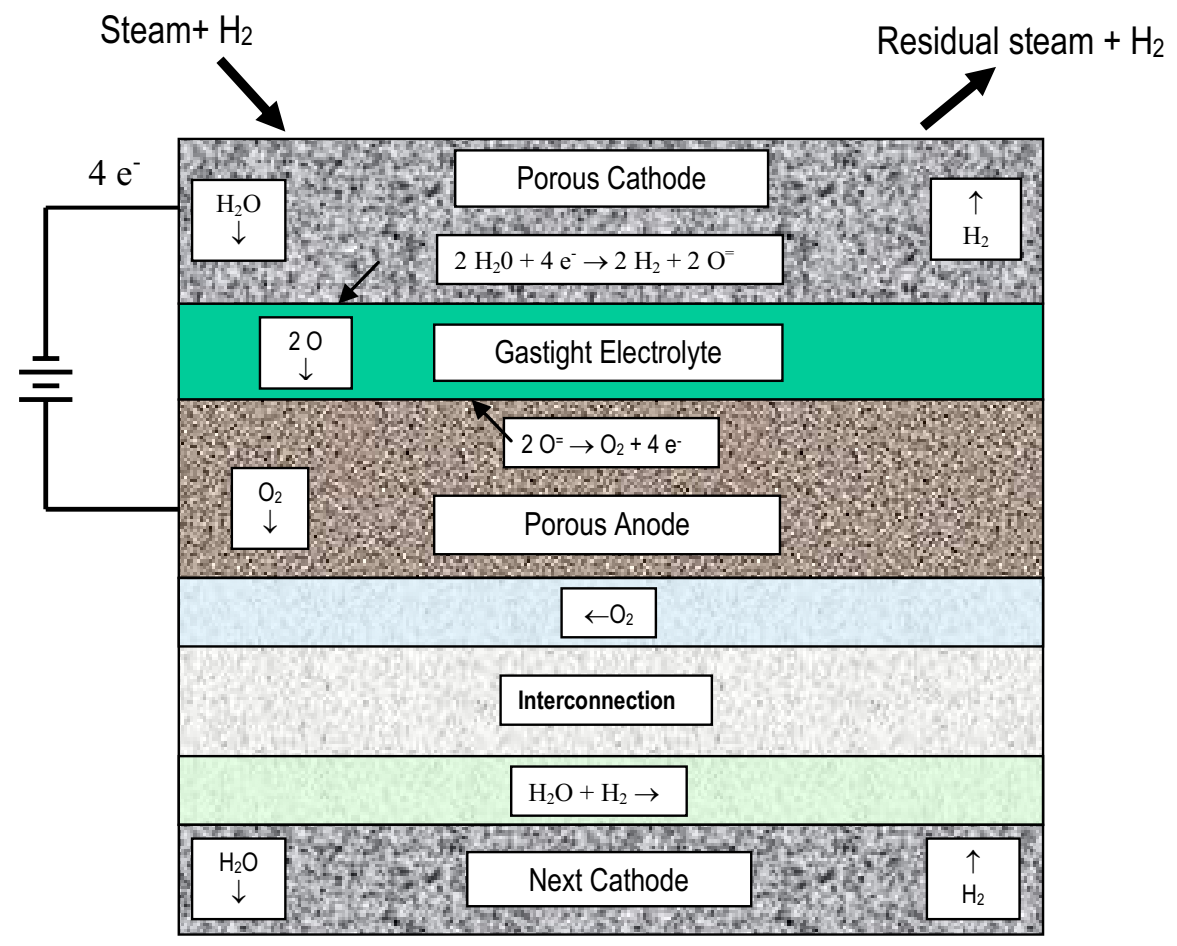

Figure 5. HTE processes in a high temperature solid oxide electrolysis cell.

\subsection{Next Generation Nuclear Plant Project}

The NGNP will demonstrate nuclear-based technology that can provide high-temperature process heat (up to $950^{\circ} \mathrm{C}$ ) and substitute for the burning of fossil fuels in a wide range of commercial applications. The substitution of the HTGR for burning fossil fuels conserves these resources for other uses, reduces our dependence on off-shore energy supplies, and eliminates the emissions of greenhouse gases from burning these fuels.

\subsubsection{NGNP Project Background}

Although there have been prior applications of nuclear gas reactor technology, the HTGR is an extension of this technology. Implementing the NGNP prototype requires significant design, licensing, and R\&D effort. Completing this effort to meet the schedule objective within a reasonable cost requires balancing the selection of initial operating conditions and the plant configuration for NGNP against the schedule and cost risks. This balance must also consider the impact of technology selections, including the hydrogen production process, on the viability of translating the NGNP demonstration to commercial applications. The principal objectives ${ }^{2}$ of the NGNP are to:

- Complete demonstration of the technical, licensing, and commercial viability of the HTGR technology in the time frame required by the EPAct

- Provide flexibility in the design to facilitate changes in the plant configuration and operating conditions to demonstrate the viability of evolving and emerging technologies over the long-term operation of the plant, (e.g., higher gas temperatures, advanced materials and component designs, advanced power conversion and hydrogen processes, advanced heat transport fluids, and future applications of high-temperature heat). 
The principal technical risks identified by the NGNP Project to the extension of the technical and licensing envelope for HTGRs include:

1. Qualification and acquisition of reactor fuel (e.g., qualification of fuel production facilities); reactor core ceramics, including graphite and graphite production facilities; and metals in the hightemperature regions of the plant (e.g., in the reactor and high-temperature system)

2. Verification and validation of analysis methods required to support design development; American Society of Mechanical Engineers (ASME) code acceptance; American Society for Testing and Materials (ASTM) standards acceptance; and NRC licensing

3. Availability of materials with acceptable metallurgical and physical properties in the required sizes and thicknesses and the ability to fabricate large vessels on-site using these materials

4. Availability and development of instrumentation (e.g., to monitor the fluence, high temperatures, and gas flow rates in the plant)

5. Development of the hydrogen production processes

6. Limit potential contamination of the product streams and meeting acceptable limits of contamination.

Of these risks, 5 and 6 are directly affected by the recommendations made in this report, and risks 2 , 3 , and 4 are affected indirectly. The NGNP operating conditions that have the most impact on the magnitude of these risks include the NGNP reactor power level and the reactor core gas inlet and outlet temperatures. These affect the required capabilities of materials in the nuclear heat supply system, which includes the heat transfer system (HTS), the power conversion system (PCS), and the hydrogen production process.

\subsubsection{NGNP Project Status}

The initiation phase for the NGNP Project is essentially complete, based on approval of the Mission Need Statement ${ }^{4}$ and approval of Critical Decision 0 (CD-0) on October 18, 2004. With CD-0 approval, the project moved into the definition phase, where alternative concepts based on user requirements, risks, costs, and other constraints are analyzed to arrive at a recommended alternative. Because of funding constraints, some design and project activities have been deferred or re-sequenced. Rough order-ofmagnitude ranges for the project cost and schedule will be developed as the project matures through the project definition phase. 


\section{ANALYSIS OF MAINTAINING A TECHNOLOGY-NEUTRAL APPROACH}

This section describes the impact of selecting a hydrogen production process at the end of the NGNP conceptual design process. Choosing a hydrogen production process for accelerated development and as the first hydrogen process for demonstration is considered an early selection, as compared to maintaining the technology-neutral schedule (e.g., deferred down-select) that is currently planned by the NHI. Design, schedule, and cost ramifications are analyzed.

\subsection{Design Ramifications}

Selecting a hydrogen production technology at the end of NGNP conceptual design requires a decision based on technologies that are relatively immature. The Government Accountability Office (GAO) identified that significant cost and schedule improvements could be realized by systematically assessing the maturity of critical technologies in large DOE projects ${ }^{5}$. The GAO recommends a disciplined and consistent approach to assessing technical readiness to inform project decision-makers as they make key decisions. Since none of the hydrogen production technologies will finish lab-scale demonstration by the end of conceptual design without accelerated testing, a rigorous systemsengineering approach that uses a standardized technical readiness scale will be employed to minimize technical risk. The NGNP Project has developed a TRL plan ${ }^{6}$ to guide technology selection decisions.

\subsubsection{Technical Readiness Levels}

TRLs were assessed for each hydrogen process to evaluate the impact of an early selection. TRLs are scales that represent the state of technological maturity of components, sub-systems, or systems as they advance from concept initiation to full-scale deployment or commercial use. TRL scales inform programmatic decisions in regard to advancement of technologies, technology down-selections, task planning, risk analyses, and allocation of resources. TRL systems use decision gates to mark passage through development phases corresponding to the TRL scale. Passage through a decision gate indicates the fulfillment of the criteria for the technology maturity that has been met. A technology must pass successfully through a gate in order to reach the next or higher development phases, as shown in Figure 6.

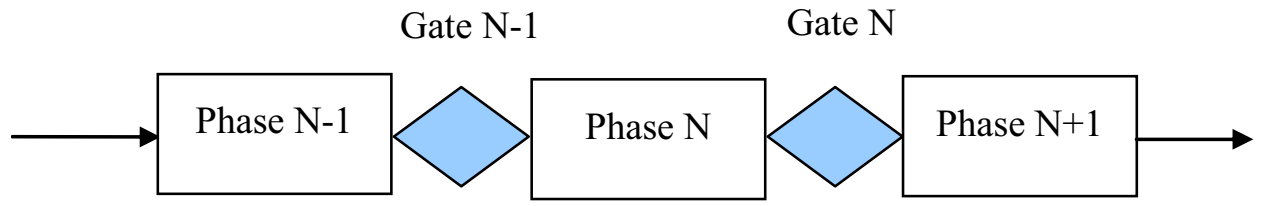

Figure 6. Phase-gate progression for TRL systems.

The NGNP is developing a TRL system to support the technology development process for the project, and an initial assignment of TRLs for the SI, HyS, and HTE processes was performed based on this system. Because the system is still being developed, criteria from three other TRL systems were used to supplement the evaluation, including the system employed by $\mathrm{NHI}^{7}$. Systems developed (or under development) by the DOE Office of Environmental Management (EM) ${ }^{8}$ and the National Aeronautics and Space Administration/Department of Defense (NASA/DoD) ${ }^{9,10}$ were also compared. These TRL systems all track technological maturity in approximately the same way but have different scales. Figure 7 shows the mapping between TRL scales. 


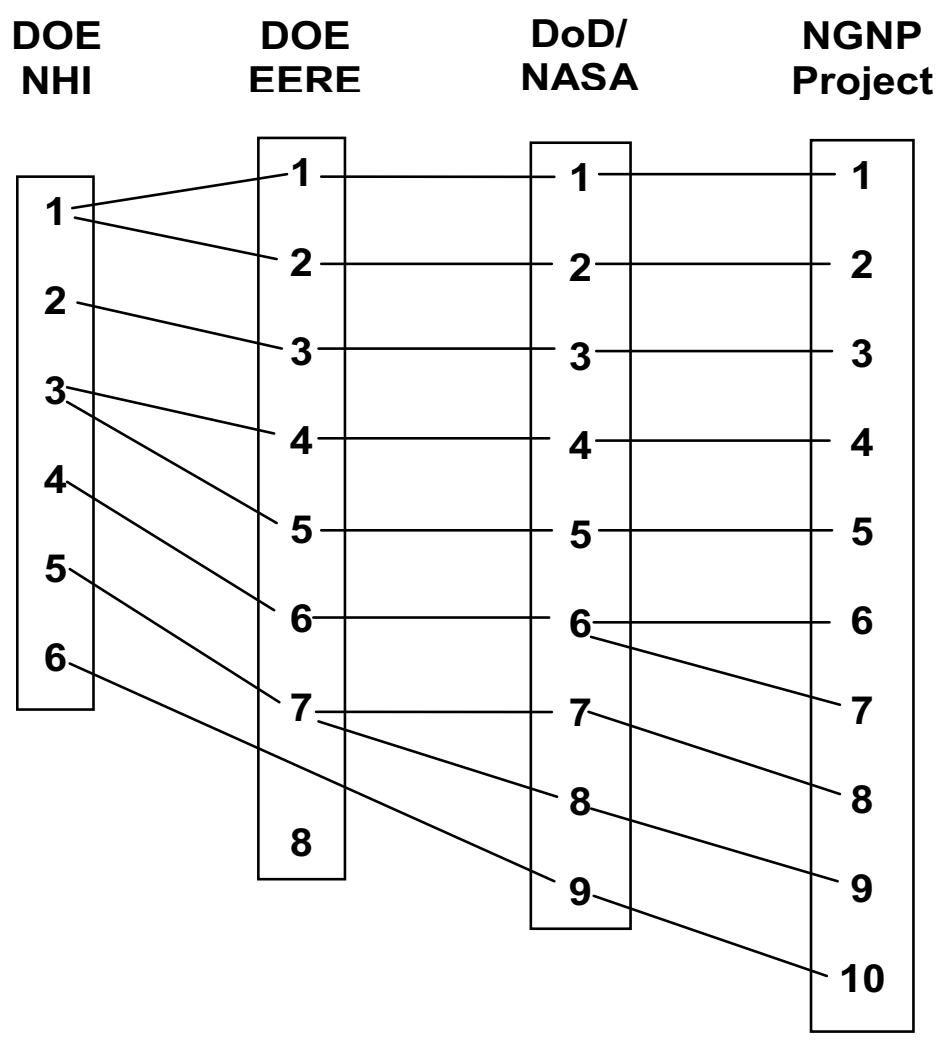

Figure 7. TRL equivalencies for NHI, EERE, DoD/NASA, and NGNP Project.

Table 1 contains a supplemented description of the criteria needed for the hydrogen production processes to advance through several TRL gates. The table is truncated to those descriptions relevant to the hydrogen process down-selection. Of note, passing through the TRL 5 gate indicates that the technology has matured enough to predict that it can be successfully developed to meet its process goals at a commercial scale. The criteria for successfully completing Phase 5 and passing through Gate 5 to the engineering-scale demonstration in Phase 6 should be defined in the pilot-scale test plan. 
Table 1. Truncated TRL phase and gate description.

TRL NGNP (supplemented) Description of TRL Phase

3 Proof-of-Concept. Analytical and experimental critical function and/or characteristic proven in the laboratory. Laboratory-scale tests performed for materials and/or components to identify/screen potential viability in anticipated service.

- Technology is incorporated into a first-generation process design, and design activities are assisted by performing analytical studies, laboratory experiments, and/or modeling and simulation.

- New technical barriers associated with moving the technology from laboratory data to process development are defined.

- Process performance barriers have been identified.

- The possible impact on other process or technology development projects being simultaneously pursued is assessed.

4 Component Validation in Laboratory Environment. Component test, experimental-scale system test, or analytical modeling validates the concept demonstrating technical feasibility and functionality. For component or breadboard/experimental-scale systems, testing is in the laboratory environment. For analytical modeling, generally recognized benchmarked computational methods and traceable material properties are used.

- Technology demonstrates functionality of process in simplified environment

- Draft process conceptual design has been documented

- Performance metrics for process have been established and documented

- Cross-technology issues have been identified

5 Component Validation in Relevant Environnent. Component experimental scale validation of the concept in relevant environment. For systems, integrated operational issues are resolved. Acceptable material or candidate materials identified and materials issues quantified for the relevant environment.

- System engineering and analysis studies that address cost, performance, integration and interfaces are completed.

- A semi-integrated/fully integrated process is assembled in the laboratory that simulates fullscale integrated operations as much as possible.

- The semi-integrated/fully integrated process is operated in the laboratory for extended testing. Results verify that when projected to full-scale, the process can meet the process targets for commercialization.

- Cross technology effects (if any) are identified and established through analysis.

6 Similar System/Subsystem/Component or Prototype Demonstration in Relevant Environment. Similar systems, subsystem, and components are used in a relevant environment but in another configuration or application.

The initial assignment of NGNP Project TRLs for the hydrogen production processes are shown in Table 2. To support the assessment, Idaho National Laboratory (INL) personnel visited each integrated laboratory-scale demonstration to review the development progress for each process. TRLs were assigned to each process by subject matter experts and NGNP systems engineers, and then reviewed with the relevant NHI technical director, NHI technical integrator, and the NGNP lead systems engineer. There is general concurrence with the initial TRL assignments. 
Table 2. Initial TRL assignments and current status.

\begin{tabular}{|lcc|}
\hline Process & Last TRL Achieved & Status \\
\hline High Temperature Electrolysis & 4 & Under Phase 5 development \\
Sulfur-Iodine Process & 4 & Under Phase 5 development \\
Hybrid-Sulfur Process & 3 & Under Phase 4 development \\
\hline
\end{tabular}

These assignments are considered preliminary until the NGNP TRL system is fully implemented. As the system is implemented, the TRLs will be updated if needed but can be used in this analysis to evaluate the relative technical risks of each process. Further, these can be used to compare the cost of completing development for the processes. When used within a rigorous systems-engineering framework, the TRLs are an essential part of making a down-selection and support other long-range planning.

\subsubsection{System Engineering-Decision Tree}

A decision tree for the down-selection of hydrogen production process technologies was developed by the NGNP Project. The purpose of a decision tree is to develop decision-making criteria, formulate alternatives, analyze performance and uncertainty associated with each alternative, and assist project management in performing risk-informed, defensible, decision analysis. It identifies the needed studies, research and development, down-selections, and driving milestones that chart the path forward to mature technologies to TRL 6. This approach is consistent with the DOE O 413.3 $\mathrm{A}^{11}$ systems requirements for the project initiation phase and determines the scheduled activities and their sequence in the project schedule. Figure 8 presents a high-level roll-up of the detailed decision tree.

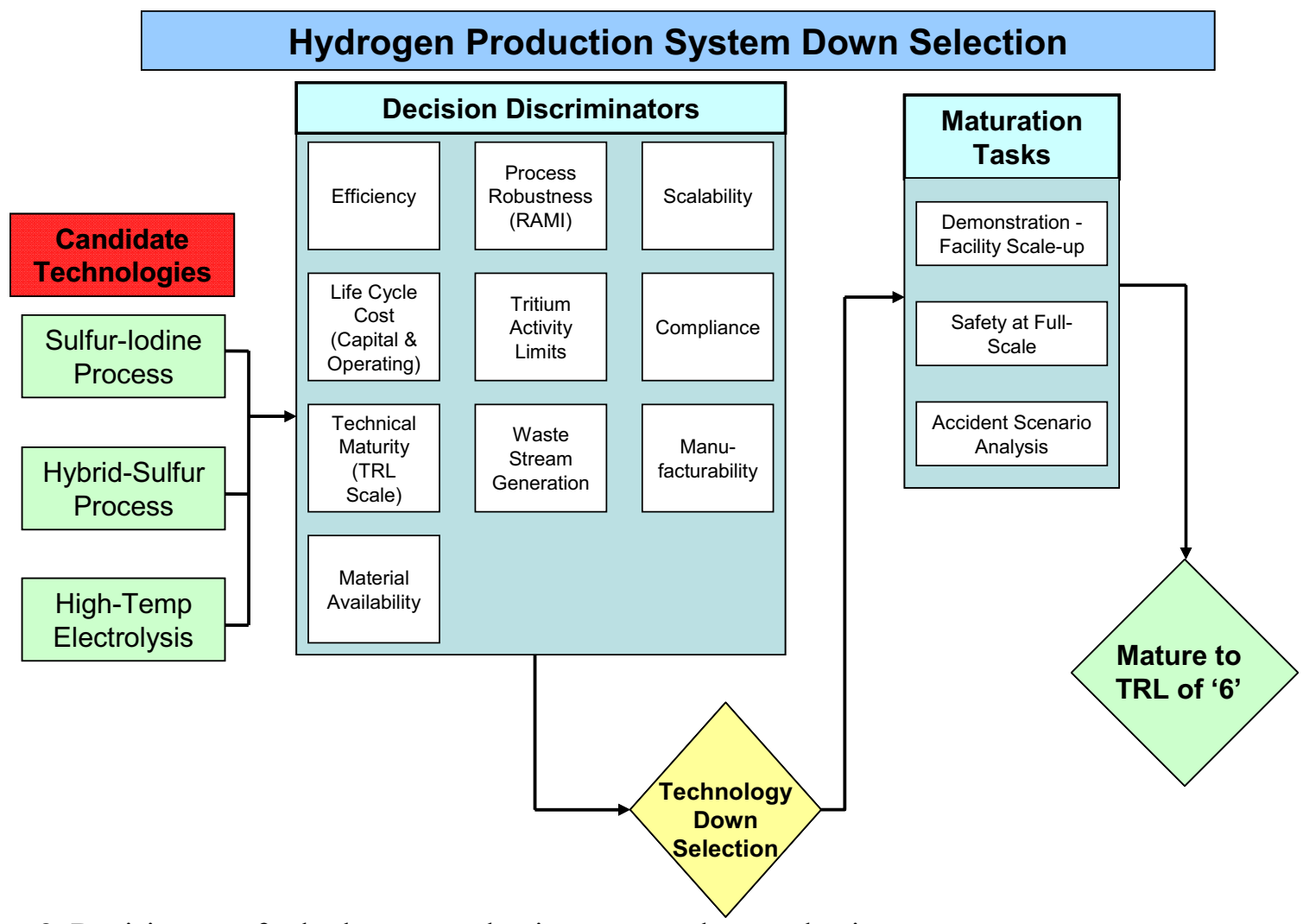

Figure 8. Decision tree for hydrogen production process down-selection. 
Ten discriminating factors were identified to inform a recommendation for a technology downselection. As noted in the previous section, the candidate technologies (SI, HyS, and HTE) are at TRL 4, 3 , and 4, respectively, on the NGNP scale, and technical maturity is one of the discriminating factors. While 10 factors are listed, the number of activities and studies will vary for each. For example, there are currently six separate tasks analyzing portions of the tritium migration allowance, while other discriminators may have only one. Instead, compliance will be assumed, and the cost of compliance will be included as part of a cost comparison. Not all of the discriminating factors will be fully analyzed by the end of FY 2008.

Also noted in the previous section was the criterion that a TRL 5 should be achieved before there is a reasonable expectation that the technology will achieve its commercial process goal. NGNP conceptual design is expected to finish no later than the end of FY 2010 (depending on funding), and none of the candidate technologies will achieve a TRL 5 by then. HyS may not achieve a TRL 4 in that period of time. Hence, comparisons of technical maturity should include an estimate of the cost and time needed to develop the process for final demonstration in addition to an evaluation of the technical risk that the process may not work as expected at a commercial scale.

It is expected that the analyses and evaluations of the discriminating factors will be completed in FY 2009 and summarized in a trade study. The study should also describe the decision-making process, assign weighting to the discriminating factors, and identify decision makers. The end-product will be a defensible down-selection recommendation that roughly corresponds to the end of NGNP conceptual design, which is consistent with DOE O 413.3A guidance for the project definition phase.

\subsection{Schedule Ramifications}

The NGNP and NHI integrated schedules provided in the following sections were compared and analyzed. Predecessor activities for milestones related to design and licensing are shown in each schedule. The integrated schedules were developed based on the critical path that shows the impact on the start of NGNP operations in 2021 and identifies the negative float where applicable. These schedules are approximate because both the NGNP and the NHI programs continue to refine schedule activities and milestones as a part of the planning process.

\subsubsection{NGNP and NHI Technology-Neutral Schedule}

The schedule in Figure 9 shows the current Technology-Neutral approach for advancing the technology development of various hydrogen production processes. This schedule shows a simplified view of the NGNP Project combined with a recent update of the NHI long-range schedule. Both schedules were reviewed and updated in May 2008 to reflect the most current approaches for NHI and NGNP. Dates are approximate and will be refined as the project matures to an approved baseline, consistent with DOE O 413.3A. It should be noted that the final hydrogen process selection is not made until the NGNP final design phase.

NGNP TRLs are shown at their present assessment and at the values that should be achieved for specific design and demonstration stages. It should be noted that while the NHI portion of the schedule shows three technologies under development until 2018, a down-selection to two processes would occur by approximately 2015 . Three processes are shown to avoid the perception that the down-selection is already determined and all dates are dependent on receiving the required funding. Several observations are apparent when the NGNP and NHI schedules are compared:

- There is sufficient time to test critical safety-significant components and systems in the CTF prior to engineering-scale testing of the hydrogen production process. Testing of the hydrogen production process would occur during the "then other components" section of the CTF schedule. 
- $\quad$ Engineering-scale demonstration in the CTF would finish at about the same time as NGNP final design and construction. Assuming there are even minimal design changes in the hydrogen process following CTF testing and subsequent destructive examination of hydrogen process components, any hydrogen process coupled to the reactor would be built after the reactor was constructed and started.

- Hydrogen production process technology development does not appear to advance in time to provide specific process information to NRC licensing activities. While the licensing process is not well defined for an advanced gas reactor, progress through the TRL stages appears to lag and may not meet the expected NRC data requirements (based on preliminary review of the Phenomena Identification and Ranking Tables [PIRT] and regulatory guides). This impacts NGNP scope and schedule as follows:

1. Assumed bounding ranges of reactor temperatures would set the limits for transients and accident scenarios, hydrogen and oxygen production rates and storage volumes, and chemical and radionuclide (tritium) inventories. The number of analyses would increase to include all reasonably possible hydrogen processes.

2. The NGNP Project intends to limit NRC regulation of the hydrogen production facilities using the $\mathrm{COL}$ process by demonstrating that active or passive controls in the reactor island or intermediate loop mitigate the effect of hydrogen process transients on the reactor. Controls must be designed based on specific hydrogen process design information. That design information will not be available in time based on the technology-neutral schedule. 
Maintaining a Technology-Neutral Approach to Hydrogen Production Process Development

Revision 0 INL/EXT-08-14193

\section{NGNP / NHI INTEGRATION - TECHNOLOGY NEUTRAL}

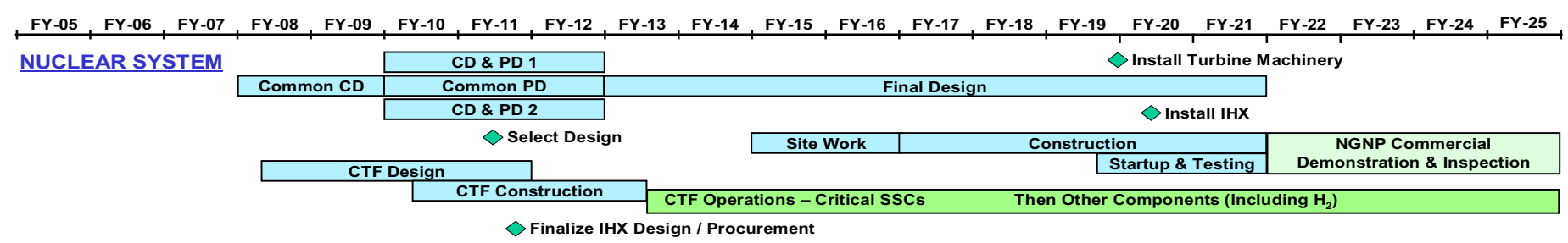

NGNP TECHNOLOGY DEVELOPMENT

$\diamond$ Complete Tritium Migration Studies, and Select Heat Transfer Fluid \& IHX Design

NRC LICENSING
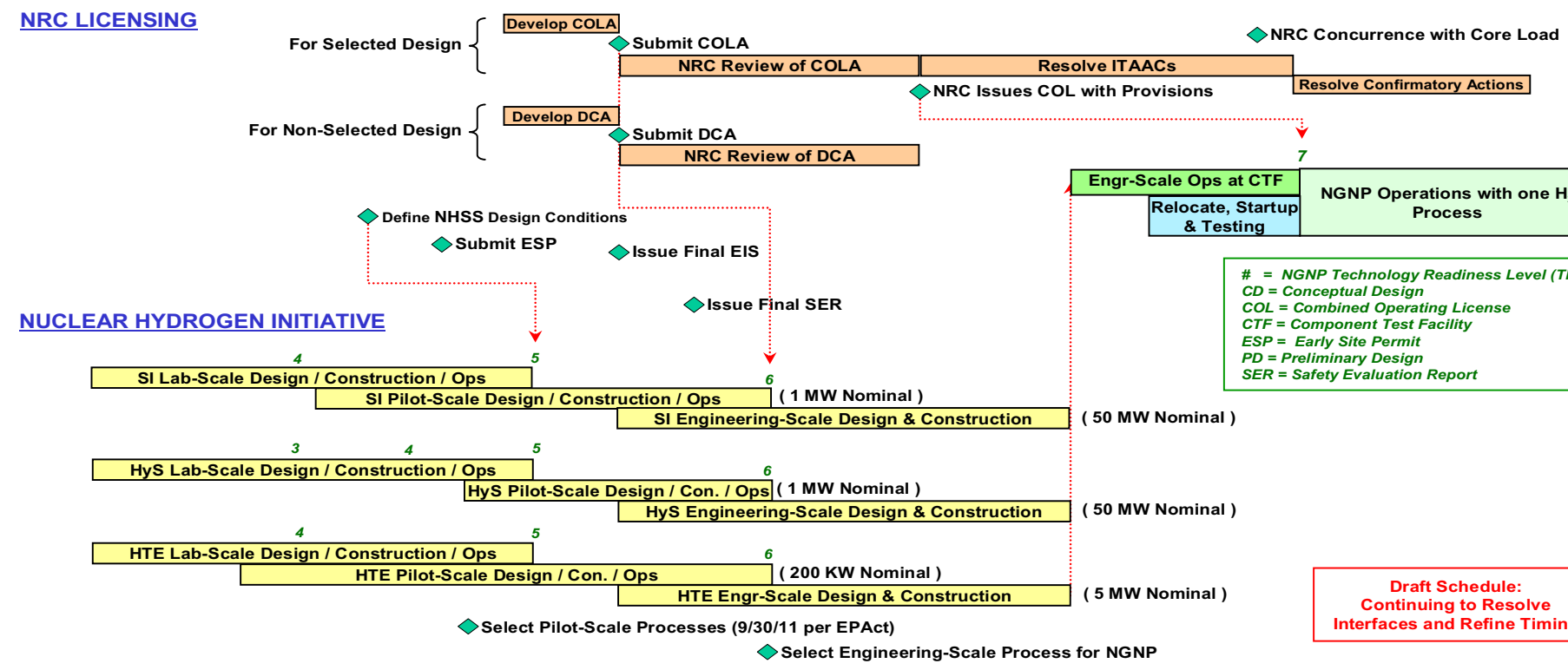

H2 Support Systems Development (HX, Infrastructure, Balance of Plant, O2 Management, etc.)

7

NGNP Operations with one $\mathrm{H}_{2}$ Process

\# = NGNP Technology Readiness Level (TRL)

$C D=$ Conceptual Design

CTF = Component Test Facilicens

ESP $=$ Early Site Permit

SER $=$ Safety Evaluation Report

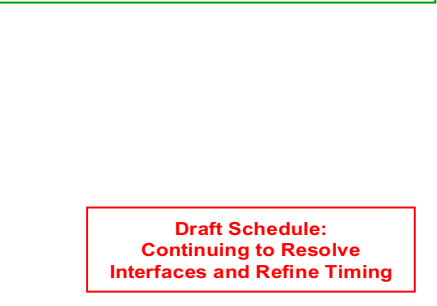

Drinuing to Resolve Interfaces and Refine Timing

NGNP-NHI Interface TN 22May08

Figure 9. NHI/NGNP Technology-Neutral schedule. 


\subsubsection{NGNP and NHI Early Selection Schedule}

The schedule in Figure 10 shows an early selection of the first hydrogen production process for demonstration, with acceleration of hydrogen development for one process to support integration with design and licensing schedules. The selection is anticipated to occur coincident with the end of NGNP conceptual design. The selection would occur before any of the hydrogen processes reached TRL 5. Several changes are apparent when the early selection schedule is compared to the technology-neutral schedule:

- Engineering-scale demonstration would occur earlier in the CTF operations schedule. The hydrogen demonstration does not have to be the first component or process demonstrated, but if CTF construction slips, it is likely that there will be conflicts between demonstration of hydrogen production plant and other critical components.

- With earlier testing in the CTF, there is time for design changes and post-test destructive examinations. Fabrication of the first hydrogen process demonstrated in the NGNP could be integrated with the reactor construction on this schedule.

- Definition of the hydrogen system design conditions in FY 2009 would still span all three production processes. This approach is consistent with typical methods for an Environmental Impact Statement (EIS) that considers all reasonable possibilities. For subsequent important licensing submissions, such as the Combined Construction and Operating License (COL), data from the pilot scale demonstrations would be available in time to inform the NRC licensing process. Information would be available in time to confirm that hazards and transients from the hydrogen production process are bounded by the interface conditions defined for the nuclear heat supply system.

- The breadth of the NRC analyses for the hydrogen process could be reduced, relative to technology-neutral approach, because one or two of the possible processes would be eliminated. 


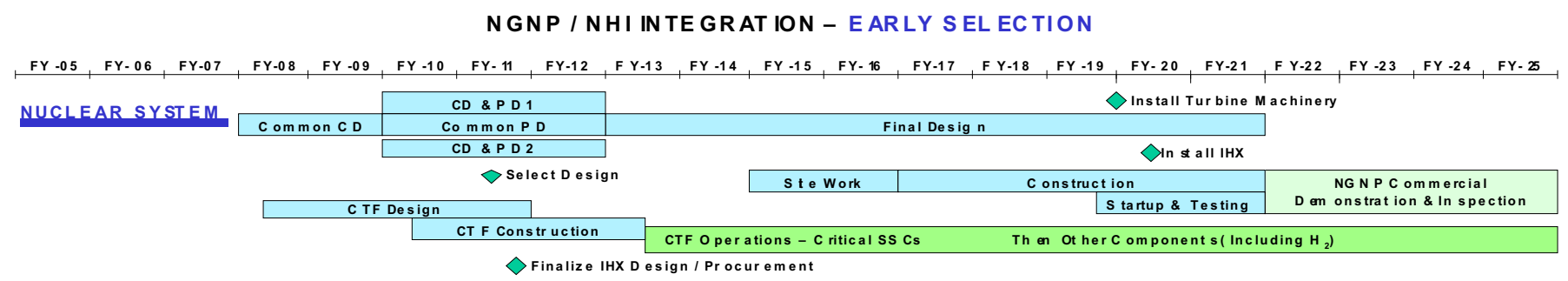

NG NP TECHNOLOGY DEVELOPMENT

Complete Triti um Migration Studés, an d Select Heat Tran sferfluid \& IHX Design

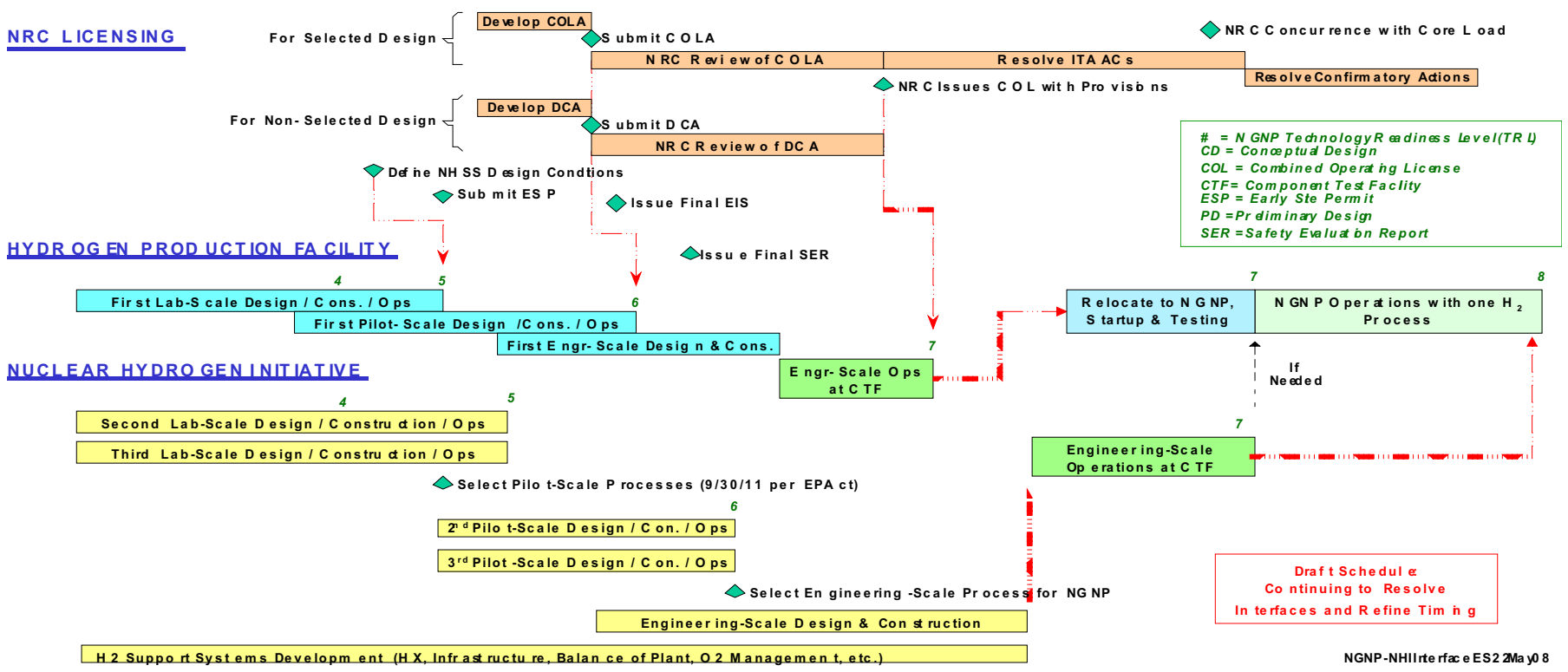

Figure 10. NHI/NGNP Early Selection schedule. 


\subsection{Cost Ramifications}

The projected costs for maintaining a technology-neutral approach and making an early selection are presented in the following sections. They are based on Field Work Proposal (FWP) estimates for the hydrogen production processes, vendor estimates, and preliminary NGNP life cycle estimates. NHI planning budgets are currently being revised based on previous funding constraints and are not specifically referenced. The total cost for each process research and development effort has been adjusted to accommodate the revised schedules presented in the previous section. While the estimates are rough and of differing levels of detail, they are adequate to identify the rough order of magnitude cost impact of making an early selection.

\subsubsection{Technology-Neutral Costs}

Technology-neutral costs assume that three laboratory-scale demonstrations will be performed, followed by a down-selection to two processes for pilot-scale demonstration, and then followed by demonstration of a single engineering-scale process. Costs presented in this section assume that the hydrogen production process is fabricated and attached to the existing CTF. Because the CTF is assumed to only house the engineering-scale demonstration, the design and construction cost of the CTF are not included. Permitting and licensing costs are assumed to be borne by the NGNP Project, and contingency and escalation costs are not included. In addition to spreading the costs for consistency with the schedule, costs were concentrated in those years where fabrication and construction were expected to occur. These costs are presented in Table 3 and are rounded to the nearest $\$ 100 \mathrm{~K}$.

Table 3. Research and development cost $(\$ \mathrm{~K})$ for technology-neutral.

\begin{tabular}{|c|c|c|c|c|c|c|c|c|c|c|c|c|}
\hline Activity & FY08 & FY09 & FY10 & FY11 & FY12 & FY13 & FY14 & FY15 & FY16 & FY17 & FY18 & \\
\hline $\begin{array}{c}\text { Number of } \\
\text { Processes } \\
\end{array}$ & 3 & 3 & 3 & 3 & 2 & 2 & 2 & 2 & 1 & 1 & 1 & Total \\
\hline SI R\&D & 2800 & 6000 & 1600 & 9.000 & 19,300 & 8,500 & 8,500 & 8,500 & 19,900 & 9,700 & 9,700 & 109,500 \\
\hline HyS R\&D & 1000 & 3000 & 1300 & 800 & 9000 & $500 \theta$ & 5,000 & 5,000 & 11,800 & 6,000 & 6,000 & 61,300 \\
\hline HTE R\&D & 1800 & $8 \% 00$ & 11.000 & 13.600 & 29,600 & 12,000 & 12,000 & $12 ; 000$ & 30,300 & 13,500 & 13,500 & 157,600 \\
\hline $\begin{array}{c}\text { ANNUAL } \\
\text { TOTAL } \\
\text { (High) }\end{array}$ & 5,600 & 18100 & 22.900 & 27.000 & 48,900 & 20,500 & $20 ; 500$ & 20,500 & 30,300 & 13,500 & 13,500 & 241,300 \\
\hline $\begin{array}{c}\text { ANNUAL } \\
\text { TOTAL } \\
\text { (Low) }\end{array}$ & 8,606 & 18100 & 22.000 & 27,000 & 28300 & 13,500 & 13,500 & $13 ; 500$ & 11,800 & 6,000 & 6,000 & 166,200 \\
\hline
\end{tabular}

Assumptions:

1. FY 2008 costs are taken from Project Information and Control System (PICS).

2. HyS total cost is taken from an NGNP cost estimate with a spread similar to HTE.

3. HTE costs are taken from the FWP, including corrosion testing and recuperator development.

4. SI costs are the approximate average of HTE and HyS costs.

5. Costs are not escalated but shown at present value for FY 2007 and FY 2008 (depending on when the estimate was performed).

Table 3 contains the R\&D costs for each of the hydrogen production processes if they are developed to completion. Together, the three total about $\$ 328 \mathrm{M}$ (not summed on the table). Assuming downselections to two technologies are performed at the end of FY 2011 and at the end of FY 2015 to one technology, the range of costs is presented as the cumulative totals for the highest annual cost and the lowest annual cost. R\&D costs for the technology neutral approach will range from \$166M to \$241M. 


\subsubsection{Early Selection Costs}

Early selection costs assume that three laboratory-scale demonstrations will be pursued until the end of FY 2009, at which time one process is selected for the first demonstration. Costs for FY 2010 and the years that follow are for one process demonstration only; although, they are presented as a range to include the choices. As with the technology-neutral approach, the costs of the CTF, licensing, and permitting are not included but assume the hydrogen production process is fabricated and attached to the existing CTF. All costs are again rounded to the nearest $\$ 100 \mathrm{~K}$, and the costs are spread to provide consistency with the early selection schedule. Escalation and contingency are excluded. These costs are presented in Table 4 below.

Table 4. Research and development cost $(\$ K)$ for early selection.

\begin{tabular}{|l|c|c|c|c|c|c|c|c|c|}
\hline Activity & FY08 & FY09 & FY10 & FY11 & FY12 & FY13 & FY14 & FY15 & \multirow{2}{*}{ Total } \\
\cline { 1 - 6 } $\begin{array}{c}\text { Number } \\
\text { of } \\
\text { Processes }\end{array}$ & $\mathbf{3}$ & $\mathbf{3}$ & $\mathbf{1}$ & $\mathbf{1}$ & $\mathbf{1}$ & $\mathbf{1}$ & $\mathbf{1}$ & $\mathbf{1}$ & \\
\hline SI R\&D & 2,800 & 6,000 & 15,200 & 18,400 & 12,200 & 23,500 & 23,500 & 7,900 & $\mathbf{1 0 9 , 5 0 0}$ \\
\hline $\begin{array}{l}\text { HyS } \\
\text { R\&D }\end{array}$ & 1,000 & 3,200 & 8,600 & 10,800 & 6,500 & 13,200 & 13,200 & 4,800 & $\mathbf{6 1 , 3 0 0}$ \\
\hline $\begin{array}{l}\text { HTE } \\
\text { R\&D }\end{array}$ & 1,800 & 8,900 & 21,900 & 26,000 & 18,000 & 35,000 & 35,000 & 11,000 & $\mathbf{1 5 7 , 6 0 0}$ \\
\hline $\begin{array}{c}\text { ANNUAL } \\
\text { TOTAL } \\
\text { (High) }\end{array}$ & 5,600 & 18,100 & 21,900 & 26,000 & 18,000 & 35,000 & 35,000 & 11,000 & $\mathbf{1 7 0 , 6 0 0}$ \\
\hline $\begin{array}{c}\text { ANNUAL } \\
\text { TOTAL } \\
\text { (Low) }\end{array}$ & 5,600 & 18,100 & 8,600 & 10,800 & 6,500 & 13,200 & 13,200 & 4,800 & $\mathbf{8 0 , 8 0 0}$ \\
\hline
\end{tabular}

Assumptions:

1. FY 2008 costs are taken from PICS.

2. HyS total cost is taken from an NGNP cost estimate with a spread similar to HTE.

3. HTE costs are taken from the FWP, including corrosion testing and recuperator development.

4. SI costs are the approximate average of HTE and HyS costs.

5. Costs are not escalated but are shown at present value for FY 2007 and FY 2008 (depending on when the estimate was performed).

Table 4 shows the same R\&D costs for each of the hydrogen production processes if they are developed to completion, as was represented in technology-neutral approach. However, Table 4 reflects the down-selection to development of one process at the end of NGNP conceptual design. Depending on which process is selected, the total $R \& D$ costs range from $\$ 81 \mathrm{M}$ to $\$ 171 \mathrm{M}$. Part of the cost avoidance is from down-selecting to development of only one process and part is from accelerating the downselection. Efficiency (versus cost avoidance) gained or lost from accelerating the total period of performance is not considered.

\subsubsection{Risk Reduction versus Cost Avoidance from Early Technology Selection}

Design, construction, and hydrogen production process demonstration when coupled with the NGNP reactor is estimated at $\$ 187 \mathrm{M}$, but this estimate is only the average of NGNP projections for all of the processes. Each cost projection is only considered accurate to $\pm 50 \%$. Hence, rough order-of-magnitude estimates for design and construction of the hydrogen process range from $\$ 94 \mathrm{M}$ to $\$ 281 \mathrm{M}$. The range is very large (which is normal in the project definition phase); hence, variations in design and construction 
costs are not precise enough yet to inform a comparison of a technology-neutral approach versus the early-selection approach. It is still included because it informs a discussion of risk.

Early selection of the hydrogen production process may avoid costs of up to $\$ 160 \mathrm{M}$ (the maximum difference between the early-selection and technology-neutral ranges). However, if an ultimately unworkable process is selected and pursued through a final demonstration with the NGNP reactor, additional costs up to $\$ 452 \mathrm{M}$ may be incurred. This cost was calculated using the sum of the high-end, early selection estimate and the upper boundary of the range for design, construction, and demonstration. It is probable that development of an unworkable process would be stopped much earlier than this, but it represents a significant financial impact if the wrong process is selected.

If a second process was selected for continued development until the first process reaches TRL 5, the combined probability and impact of selecting the wrong process would be substantially reduced.

Continuing development of the second process would not need to proceed at the same rate as the primary selection. If a second process was funded at the same rate shown in the technology-neutral profile for about 2 years, substantial risk mitigation could be provided for between $\$ 9 \mathrm{M}$ and $\$ 24 \mathrm{M}$. This represents $2 \%$ to $5 \%$ of the total funding at risk, and it is concluded that continuing development of a second process until the first process reaches TRL 5 is a reasonable risk reduction measure.

Another opportunity for cost avoidance exists. The CTF is being designed to perform an engineering scale hydrogen production demonstration the same size as the NGNP-coupled demonstration. Therefore, the CTF could perform the same demonstration as the VHTR and meet the intent of the EPAct (which ties demonstration of hydrogen production to the NGNP). The design, construction, and operating costs for the NGNP-coupled demonstration $(\$ 94 \mathrm{M}$ to $\$ 281 \mathrm{M}$ ) could be completely or partly avoided. Revision of the EPAct to decouple the hydrogen demonstration from NGNP would be required. 


\section{RECOMMENDATIONS}

Recommendations are listed in the form of risk mitigation, whether they are for design, cost, or schedule impacts. In most cases the recommendations span all of the categories. Continued collaboration is listed separately; although, it is a project and technical risk mitigation strategy also.

\subsection{Risk Mitigation}

The following activities are recommended as a result of this evaluation. In some cases there is overlap, and they are not quantified. The activities should serve as a starting point for the development of a hydrogen production section in the NGNP Project risk management plan.

- Complete a rigorous life cycle cost estimate and associated schedule for development and demonstration of each hydrogen production process. The assumptions should be consistent for each estimate, and the schedule should be integrated with the NGNP Project elements for design, construction, and licensing. The estimates and schedule should apply statistical tools to quantify uncertainty, establish a cost, and schedule range and be integrated with the NGNP risk management plan. Activities on the schedule should align with PIRT analyses and design data needs. The NHI and NGNP integrating schedule activities and milestones should be consistently identified and defined.

- Clearly define data needs with regard to hydrogen production process design information and transient modeling. Timing of pilot-scale testing should be considered so that the information is available to confirm that hazards and transients from the hydrogen production process are bounded by the NRC licensing interface conditions defined for the nuclear heat supply system.

- Perform the activities informing the decision tree discriminating factors in support of a downselection. Down-selection prior to reaching TRL 5 imposes technical risks because of process maturity, and gathering the information for the decision tree reduces this risk.

- Continue development of a second hydrogen process for about 2 years after the down-selection. For $2 \%$ to $5 \%$ of the hydrogen development budget, a back-up process is provided in the event the first selection is not viable. Discontinue development of the second process when the original selection reaches TRL 5. This approach provides about 2 years of float on the schedule for the first process to reach TRL 5 or to make a decision to switch if the first process does not mature technically.

- Design the CTF so that it is compatible with any of the hydrogen production processes. By the time a final down-selection is made, the CTF will probably be in construction. Also, subsequent hydrogen production processes may be more promising and will need an engineering-scale demonstration platform.

- Decide now if an engineering-scale demonstration in the CTF meets EPAct requirements. There is the potential for large cost avoidances and schedule improvements if the hydrogen production process does not need to be coupled to the reactor, but it is probable that agreement on this approach will take lengthy discussion. In particular, the impact on National Environmental Policy Act (NEPA) activities for the CTF should be considered.

\subsection{Continued Collaboration of NGNP and NHI}

The forgoing analyses demonstrate the need for close and formal collaboration between the NGNP Project and NHI to ensure that NHI activities and schedules affecting the NGNP Project meet its needs. Development of heat transfer and transport system components and the NGNP hydrogen production process have been part of NHI, but have significant impact on the NGNP design, licensing and schedule. NHI's programmatic purpose to develop heat transfer/transport and hydrogen production technologies coupled to nuclear reactors is, in general, broader than the NGNP Project objectives. The NGNP 
Project's specific design, licensing, development and commercialization-support objectives are directed toward establishing the technical and licensing basis for the HTGR technology to provide process heat to a broad range of potential end-user applications, including the production of hydrogen. The NGNP Project needs to choose the best available heat transfer/transport and hydrogen production technologies that are technically and economically viable, and support the project schedule. NHI should be expected to continue pursuing alternative hydrogen process technologies that improve the economics, and technical and environmental viability extending beyond the NGNP Project. Accordingly,

- The schedule and objectives for NHI process development activities that affect the NGNP heat transfer and transport systems and the development of interface requirements for the hydrogen process and other factors affecting the design and licensing of NGNP, (e.g., establishing external hazards, transient responses to upset in the hydrogen production facility, etc.) should be set by the NGNP Project.

- Funding for these activities should be included in the budget of, and be controlled by, the NGNP Project.

- The requirements and funding for completion of NHI commitments to the NGNP Project should be established and controlled through close collaboration and formal agreements, (e.g., future contracts) between the NHI program and the NGNP Project that support the design, licensing and schedule for NGNP.

In this regard, these agreements should formalize the recently developed divisions of responsibility in these areas; specifically, that the NGNP Project is responsible for maintaining the heat transport systems interface function, whereas NHI maintains responsibility for hydrogen production process R\&D technical integration. The following provides further recommendations for detailed responsibilities in the areas.

The NGNP project shall be responsible for:

- Transient modeling of heat transport systems coupled to the hydrogen process - reactor interface

- Materials demonstration and development of heat exchangers and coupled equipment

- TRL definition and technology development roadmaps, integrated with NHI test plans

- NGNP project analyses related to hydrogen process design data needs and PIRT scenarios

- Contract mechanisms (if needed) to allow NHI personnel to interact with NGNP vendors

- Design and fabrication of the engineering-scale hydrogen production process to be tested in CTF and that is to be installed and demonstrated in NGNP

- Development and monitoring of formal agreements for work to be completed by the NHI program to support the NGNP Project needs

The NHI shall continue responsibility for:

- Technical responsibility for R\&D of prospective hydrogen processes through engineering-scale demonstration

- Development of test plans for the pilot- and engineering-scale demonstrations, integrated with NGNP TRL definition and development of technology roadmaps

- Materials demonstration and development downstream of the NGNP process heat exchanger 
- Definition of hydrogen product storage capability

- Hydrogen process chemical hazards description

- $\quad$ Completion of the above and other work as specified in the formal agreements with the NGNP Project within required schedule and budget 


\section{SUMMARY}

The NGNP Project team analyzed the design, cost, and schedule impact of maintaining a technologyneutral approach for hydrogen process development through conceptual design of the NGNP. Currently, the NHI is performing parallel R\&D on three hydrogen production processes - a technology neutral approach. While the objectives of the NGNP Project and NHI are consistent, comparisons of the individual schedules show that the NHI schedule does not meet the needs of the NGNP Project. Specifically, NHI plans to select two hydrogen processes for further development in 2011 and recommend a final process for demonstration in 2015. The NGNP Project expects to complete conceptual design at the end of FY 2010, at which time the hydrogen process to be demonstrated should be selected. This analysis compares acceleration of the hydrogen process down-selection at the completion of the NGNP Project conceptual design to the current NHI plan. It was performed to improve integration of the hydrogen process development and NGNP Project schedules, and fulfills milestone G-IN07NG07-90 Complete an analysis of the design, cost and schedule ramifications for maintaining a technology neutral hydrogen production process for NGNP through the conceptual design phase.

The NGNP Project intends to design and construct a prototype HTGR. A component test facility is planned to support testing and demonstration of HTGR technologies, including those for hydrogen production. The demonstrations will support scheduled design and licensing activities, leading to subsequent construction and operation of the HTGR. Demonstrations in the CTF are expected to start about two years earlier than similar scale hydrogen process demonstrations planned by NHI. Selection of the hydrogen process to coincide with the end of NGNP conceptual design will reconcile many of the schedule conflicts and hence, was chosen as basis for schedule acceleration. The principal results, conclusions and recommendations of the analysis are as follow:

- Accelerating the schedule to maintain a technology neutral approach only until the completion of conceptual design and then making an early selection of the hydrogen process for NGNP is feasible and recommended. In part, as a result of reduction in the current funding for the NHI program, this early selection in FY 2010, however, may occur before the development of the candidate hydrogen process technologies have progressed to the point that predicts success at a commercial scale. It is recommended therefore, that the hydrogen production process down-selection should identify the primary hydrogen process for demonstration and also a back-up process if the primary process development is not successful. Development of the back-up process should continue at a slower pace until the primary process reaches TRL 5 on the NGNP technical readiness scale, which indicates the technology is likely to successfully scale up to commercial application. Maintaining development of the back-up process for a short period of time is an affordable and reasonable risk management strategy.

- Cost avoidance from early selection may be as high as $\$ 160$ million. This maximum cost avoidance results from eliminating work on all unselected processes and depends on which process is selected for demonstration. Developing a back-up process reduces the cost avoidance by $\$ 9$ million to $\$ 24$ million, depending on which process is chosen as the back-up. Current cost estimates are very immature and only a rough order of magnitude, but sufficient to identify that significant savings can be realized. Development of a rigorous life cycle cost estimate and schedule for each hydrogen production process is recommended. This information should be used in establishing a long-term plan that is consistent between the NGNP Project and NHI, and should also inform future decisions. 
- As part of the analysis of design ramifications, a systems-engineering approach was used to define the decision-making process and criteria for selecting the primary and back-up hydrogen processes. These are summarized in Figure 8. Decision tree for hydrogen production process down-selection. Performance of these activities during conceptual design is recommended to discriminate between hydrogen technologies and inform the process selection.

- The NGNP Project will rely heavily on engineering scale testing of the hydrogen process in the CTF to prove the technical capabilities and reliability of the process before installation in the HTGR. CTF is currently expected to be available for testing in FY 2014 and it is important that the design of the CTF and the schedule for testing in this facility support the timely development of the selected process. It is recommended that the development of the functional and operating requirements and configuration of the $\mathrm{CTF}$ accommodate testing any of the hydrogen processes under consideration at a commercial scale.

- An early selection will accelerate hydrogen process testing in the CTF and provide more timely and necessary data required for support of NGNP licensing by the NRC. For example, establishing hazards and transient operating conditions will support development of bounding interface conditions to be used in design and licensing of the nuclear heat supply system.

- Additional evaluations of the feasibility and advantages of use the CTF, rather than NGNP, to perform the commercial-scale demonstration required by the EPAct are recommended. The evaluation should include analysis of the need to revise the EPAct.

Finally, this effort has demonstrated the need to have better coordination of the NGNP and NHI program objectives and schedules. The NHI's programmatic purpose to develop hydrogen production technologies that can be coupled to nuclear reactors is broader than the NGNP Project's objective regarding hydrogen production. The NGNP Project's specific design, licensing, development and commercialization-support objectives are directed toward establishing the technical and licensing basis for the HTGR technology to provide process heat to a broad range of potential end-user applications including the production of hydrogen as an energy carrier. The Project needs to choose the best available hydrogen production technology that is technically and economically viable, and supports the project schedule.

NHI could be expected to continue pursuing alternative technologies that improve the economics, and technical and environmental viability with a development schedule that may extend beyond the NGNP Project. Accordingly, the schedule and objectives for NHI process development activities that affect the NGNP heat transfer and transport systems and the development of interface requirements for the hydrogen process and other factors affecting the design and licensing of NGNP, (e.g., establishing external hazards, transient responses to upset in the hydrogen production facility) must be set by the NGNP Project. Funding for these activities by NHI should be included in the budget of and be controlled by the NGNP Project. The requirements and funding for completion of NHI commitments to the NGNP Project shall be established and controlled through close collaboration and formal agreements, (e.g., future contracts) between the NHI and the NGNP Projects that support the design, licensing and schedule for NGNP. Section 4.2 of the report summarizes responsibilities of NHI and NGNP in this regard. 


\section{REFERENCES}

1. Energy Policy Act of 2005 (EPAct), signed by President Bush on August 8, 2005

2. NGNP Preliminary Project Management Plan PLN-2489 (INL/EXT-05-00952) Revision 1 dated March 2008

3. Nuclear Hydrogen Initiative Ten Year R\&D Program Plan (FY2007 Update) U.S. DOE Office of Nuclear Energy Advanced Nuclear Research, March 2007

4. Mission Need Statement NGNP Major System Acquisition Project, dated September 24, 2004, CD-0 Approved October 18, 2004.

5. Department of Energy - Major Construction Projects Need a Consistent Approach for Assessing Technology Readiness to Help Avoid Cost Increases and Delays U.S. Government Accountability Office Report GAO-07-336, March 2007

6. NGNP Technical Readiness Level Plan, INL/EXT-08-14251, Revision 0 dated May 12, 2008

7. Steven R. Sherman letter to Michael W. Patterson dated April 18, 2008, Subject: Initial TRL Assignments for Nuclear Hydrogen Production Methods, Letter number WSRC-TR-2008-00121

8. U.S. DOE Office of Environmental Management Technology Readiness Assessment (TRA) / Technology Maturation Plan (TMP) Process Guide, Dated March 2008

9. NASA Research and Technology Program and Project Management Requirements, NASA Procedural Requirements 7120.8, Appendix J. Technology Readiness Levels (TRLs), Effective Date: February 05, 2008

10. DOD Technology Readiness Assessment (TRA) Deskbook, May 2005

11. Program and Project Management for the Acquisition of Capital Assets U.S. DOE Order 413.3A, Approved July 28, 2006 